J Phys Chem B. 2018 December 13; 122(49): 11519-11534. doi:10.1021/acs.jpcb.8b07405.

\title{
Static Kinks or Flexible Hinges: Multiple Conformations of Bent DNA Bound to Integration Host Factor Revealed by Fluorescence Lifetime Measurements
}

\author{
Mitchell Connolly ${ }^{\dagger}$, Aline Arra ${ }^{\dagger}$, Viktoriya Zvoda $^{\dagger}$, Peter J. Steinbach $\Uparrow$, Phoebe A. Rice ${ }^{\S}$ \\ Anjum Ansari ${ }^{\dagger, \ddagger},{ }^{*}$ \\ tDepartment of Physics, University of Illinois at Chicago, Chicago, IL 60607, USA \\ "Center for Molecular Modeling, Center for Information Technology, National Institutes of Health, \\ Bethesda, MD 20892, USA \\ $\S$ Department of Biochemistry \& Molecular Biology, University of Chicago, Chicago, IL 60637, USA \\ ‡Department of Bioengineering, University of Illinois at Chicago, Chicago, IL 60607, USA
}

\begin{abstract}
Gene regulation depends on proteins that bind to specific DNA sites. Such specific recognition often involves severe DNA deformations including sharp kinks. It has been unclear how rigid or flexible these protein-induced kinks are. Here, we investigated the dynamic nature of DNA in complex with integration host factor (IHF), a nucleoid-associated architectural protein known to bend one of its cognate sites ( 35 base pair H') into a U-turn by kinking DNA at two sites. We utilized fluorescence-lifetime-based FRET spectroscopy to assess the distribution of bent conformations in various IHF-DNA complexes. Our results reveal a surprisingly dynamic specific complex: while 78\% of the IHF-H' population exhibited FRET efficiency consistent with the crystal structure, 22\% exhibited FRET efficiency indicative of unbent or partially bent DNA. This conformational flexibility is modulated by sequence variations in the cognate site. In another site (H1) that lacks an A-tract of H' on one side of the binding site, the population in the fully U-bent conformation decreased to $32 \%$, as did the extent of bending. A similar decrease in the U-bent population was observed with a single base mutation in $\mathrm{H}^{\prime}$ in a consensus region on the other side. Taken together, these results provide important insights into the finely tuned interactions between IHF and its cognate sites that keep the DNA bent (or not), and yield quantitative data on the dynamic equilibrium between different DNA conformations (kinked or not kinked) that depend sensitively on DNA sequence and deformability. Notably, the difference in dynamics between IHF-H' and IHF-H1 reflects the different roles of these complexes in their natural context, in the phage lambda "intasome" (the complex that integrates phage lambda into the E. coli chromosome).
\end{abstract}

\section{Graphical Abstract}




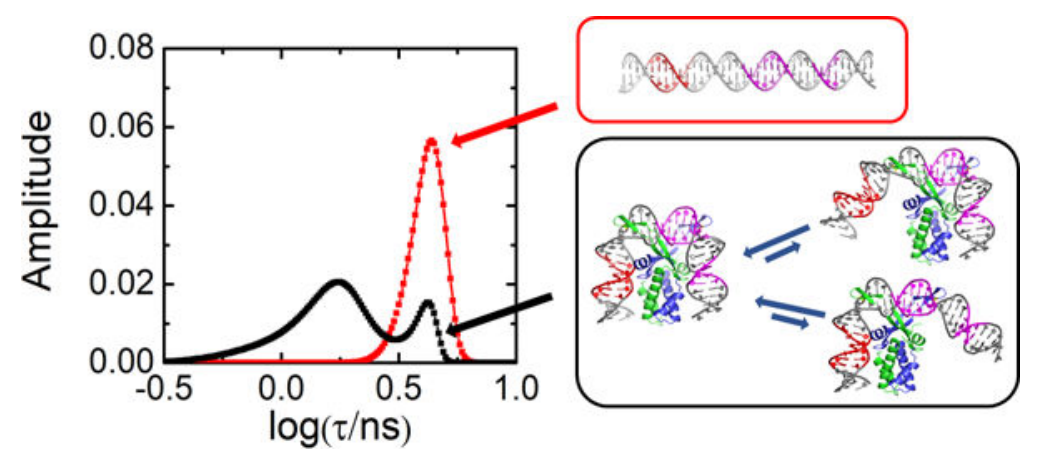

\section{INTRODUCTION}

Severe distortions to the B-DNA structure are ubiquitous in the cell and are induced not only by nonspecific DNA packaging proteins but also by site-specific proteins when they bind to their target sites on DNA for gene regulation, replication and repair. These distortions often appear as DNA bends or localized kinks that range from $\sim 30^{\circ}$ kinks per helical turn when wrapped in the nucleosome, ${ }^{1-4}$ to more severe kinks of $\sim 80-90^{\circ}$ in several site-specific DNA bending proteins, ${ }^{5-8}$ to what may be the most severely bent DNA conformation found in complex with the IHF/HU family of bacterial type II DNA-bending proteins. ${ }^{9-11}$ While structural studies on many DNA-bending protein complexes have revealed the nature of these DNA distortions at atomic resolution, the behavior of the distorted, sharply kinked, DNA in solution needs further study. One question that has yet to be fully resolved is whether these distorted DNA structures behave as rigid kinks in solution or as flexible hinges. ${ }^{12}$ Precise measurements of the accessible protein-DNA conformations in solution are needed to elucidate the functional roles of these dynamic fluctuations as well as to provide experimental checkpoints in the development and improvement of computational models of sequence-dependent DNA deformability and stabilization of bent DNA by proteins. ${ }^{13-22}$

Several lines of evidence suggest that DNA in nonspecific complexes indeed adopts a range of bent conformations. Evidence for conformational heterogeneity is well documented in the case of the nonspecific architectural histone-like nucleoprotein HU that is known to bend DNA into a U-shape. ${ }^{10,23}$ Indirect evidence for multiple bent states in HU-DNA complexes came from multiple bands revealed in gel shift assays, ${ }^{24}$ and from different degrees of bending observed in different crystal structures of these complexes. ${ }^{10}$ This heterogeneity in HU-DNA complexes was directly confirmed from atomic force microscopy (AFM) studies that showed a broad distribution of bent conformations with bend angles observed in the entire range from 0 to $180^{\circ} .{ }^{25}$ It is perhaps not too surprising that a nonspecific architectural DNA bending protein, especially one that has a variety of biological roles, would exhibit such broad conformational heterogeneity, given the lack of specific contacts that would otherwise compensate for the energetic penalty required to severely deform DNA.

However, are specific complexes with DNA-bending proteins also conformationally heterogeneous? AFM studies on some specific complexes have revealed relatively broad distributions of bend angles, although the resolution of these AFM studies primarily revealed single-peaked distributions of varying widths, consistent with thermal fluctuations 
within a single free energy well in the conformational landscape of the complex. ${ }^{26-28}$ Notable exceptions in which two or more distinct bent states of DNA are observed include mismatch repair protein MutS ${ }^{29}$ and DNA glycosylase hTDG $^{30}$ bound to mismatched DNA. Interestingly, these are examples of complexes with DNA damage recognition proteins in which the specific site is typically a single mismatch or a single chemically modified base, and all other interactions of the protein with the flanking DNA sequences are nonspecific. For site-specific proteins that bind to canonical, undamaged DNA, and for which the target site extends beyond a few base pairs, data are scarce regarding conformational heterogeneity in such complexes.

Here, we present results that quantify the heterogeneity of bent DNA conformations when bound to the eukaryotic DNA-bending protein, the Escherichia coli integration host factor (IHF). We utilized picosecond-resolved fluorescence lifetime measurements to identify multiple FRET states, which reflect the distribution of bent conformations in the IHF-DNA complex. The lifetime approach has a few advantages over single-molecule assays of FRET distributions. ${ }^{31}$ Measurements are done under solution conditions and thus avoid many of the issues that may come with immobilization of protein-DNA complexes as needed for AFM studies ${ }^{32-33}$ or single-molecule FRET (smFRET) studies, ${ }^{34-37}$ although smFRET on freely diffusing molecules do alleviate immobilization issues, as showcased in a series of elegant papers by Eaton and co-workers ${ }^{38-41}$ on the dynamics and distributions during protein folding. More important, fluorescence decay curves measured in bulk solution provide significantly better resolution of the shape of the FRET efficiency distributions than can be obtained from single-molecule studies where the number of molecules sampled are of $\mathcal{O}\left(10^{2}\right)$ to $\mathcal{O}\left(10^{4}\right)$. Moreover, the time resolution of the lifetime studies enables snapshots of the conformational distribution with an effective "shutter speed" that is typically less than tens of nanoseconds (within the excited state lifetime of the fluorophore). In smFRET, the observation time window is few milliseconds or longer, which can obscure conformational heterogeneity if dynamic fluctuations between different conformations are faster than a few milliseconds. ${ }^{42}$ Recently, we demonstrated the effectiveness of fluorescence lifetime based FRET measurements in unveiling the conformational heterogeneity in mismatched DNA bound to nucleotide excision repair protein XPC/Rad4, with evidence for two or more distinct DNA conformations in the complex. ${ }^{43}$

Here we focus on IHF, which is a small ( $22 \mathrm{kDa}$ ) bacterial heterodimeric nucleoidassociated protein that is closely related to $\mathrm{HU}$ and structurally very similar. ${ }^{23,} 44$ Unlike HU, however, IHF binds DNA both nonspecifically, in its role as a DNA compaction protein, and specifically, when required for site-specific recombination, DNA replication and transcription. IHF also recognizes several sites on bacteriophage lambda DNA in its role as a host factor for lysogeny by phage lambda. ${ }^{45-46}$ The footprint of DNA bound to IHF exceeds 25 base pairs (bp) ${ }^{47}$ However, the consensus sequence identified on the basis of a large number of cognate sites for IHF consists of two short elements in one half of the footprinted region (Figure 1): WATCARnnnnTTR, where $\mathrm{W}$ denotes A or T, R denotes purine, and $n$ refers to any base. ${ }^{47-48}$ Some IHF sites also contain an A-tract containing 4-6 adenines and located in the other half of the binding site. ${ }^{49-50}$ 
The crystal structure of IHF bound to one such cognate site, denoted as the H' site (Figure 1 and Table 1), showed that IHF sharply kinks the DNA at two sites spaced $\sim 9$ bp apart, explaining how it can bring distal regions of DNA together to facilitate the formation of higher-order nucleoprotein complexes. ${ }^{9}$ The kinks in the DNA are stabilized by conserved proline residues located on two $\beta$-ribbon arms of the protein. The arms are thought to be flexible in the absence of the DNA but wrap around the DNA in the complex and make additional stabilizing contacts in the consensus region between the kink sites (Figure 1). Further stabilization needed to overcome the large energy penalty for the sharply kinked DNA comes from additional contacts between the flanking DNA segments and the core of the protein dimer, as well as from an extensive network of electrostatic interactions with charged residues of the protein and the phosphates in the DNA backbone. ${ }^{51-52}$

All contacts that IHF makes with the DNA in the specific complex are either in the minor groove, where the hydrogen bonding patterns offered by the different bases are very similar, ${ }^{53}$ or to the sugar phosphate backbone. Thus, IHF is a remarkable example of a DNA-bending protein that exhibits high specificity to certain sequences but relies almost exclusively on "indirect readout" to recognize its target sequence; i.e. it recognizes sequence-dependent DNA shape, local geometry, and DNA deformability without the need for direct recognition of the specific bases by the protein residues. ${ }^{54}$ Several features within the binding site play a role in facilitating this recognition. One may be the ease with which the two sites can be kinked: although only one kink occurs within the consensus sequence, introducing single-T insertions or mismatches to make the DNA more flexible at these sites was shown to increase the binding affinity for IHF as well as for the nonspecific HU. ${ }^{55-56}$ Another important feature is the flanking DNA sequences that interact with the sides of the protein, where the minor groove of the DNA is clamped between the N-termini of two alpha helices. On the right side (as shown in Figure 1 and Table 1), the TTR of the consensus sequence allows over-twisting of the DNA that facilitates its fit into the protein clamp and the formation of salt bridges with the side chains of $\mathrm{IHF}^{57}$ On the left side of $\mathrm{H}^{\prime}$ (but not all IHF binding sites) is an A-tract. The structure shows that the unusually narrow groove naturally adopted by A-tract DNA fits well into the protein clamp, and this may explain why crystals could not be grown with IHF binding sites that did not include the A-tract. ${ }^{9}$ This study seeks to elucidate how each of these features help keep the DNA bent and clamped against the protein and to what extent the DNA resists these bending deformations.

The fluorescence lifetime-based FRET measurements presented here demonstrate that IHF bound to a 35-bp substrate containing the cognate H' site, the sequence used in the crystal structure, in fact samples at least two distinct states: a high-FRET state that appears to be fully bent, as in the crystal structure, and a low-FRET state consistent with partially bent DNA that could include an ensemble of conformations with one side unclamped or the other. Another cognate site that is lacking the A-tract (the H1 site on phage lambda DNA) showed a significantly smaller population in the fully bent state, highlighting the effectiveness of the A-tract to keep that side of the DNA clamped down. The population in the fully bent state in the IHF-H1 complex is partially recovered when mismatches are introduced at the kink site near the missing A-tract, to reduce the energetic cost of kinking the DNA at that site. Finally, a single base modification in the TTR consensus region in the other flanking arm, previously known to destabilize the complex, also resulted in a significantly diminished population 
in the fully bent state. Taken together, these results provide additional insights into the finely tuned interactions between IHF and its cognate sites that keep the DNA bent (or not) and yield quantitative data on the populations of different DNA conformations (kinked or not kinked) that are sensitively dependent on the DNA sequence and deformability. These results also correlate well with the biological function of the two IHF-binding sites studied. These two sites are found within the large protein-DNA complex responsible for integrating phage lambda DNA into the $E$. coli chromosome, and structural modeling shows that the IHF-induced bend at the $\mathrm{H} 1$ site, but not at the bend $\mathrm{H}^{\prime}$ site, must flex during assembly. ${ }^{58}$

\section{EXPERIMENTAL METHODS}

\section{Materials}

The DNA sequences used in this study are shown in Table 1. All labeled and unlabeled DNA oligomers were ordered from Keck (with gel purification) or from IDT (with HPLC purification). Two different labeling strategies were used as shown in Table 1: in design I constructs, fluorescein (F) and TAMRA (R) were attached to $\mathrm{C} 5$ of single-thymidine overhangs at the 5'-end of the top and bottom strands, respectively, through six-carbon linkers; in design II constructs, fluorescein (F) was attached to C5 of a thymidine located 10 nucleotides from the 3 '-end of the top strand and two base pairs away from one of the kink sites, and Atto550 (At) was attached to the bottom strand, to the phosphate group of the DNA backbone at the 3' end, also by six-carbon linkers.

DNA concentrations were determined by absorbance measurements at $260 \mathrm{~nm}$, with extinction coefficients $3.58 \times 10^{5} \mathrm{M}^{-1} \mathrm{~cm}^{-1}$ for the 5'-end F-labeled (top) strand, $3.66 \times 10^{5}$ $\mathrm{M}^{-1} \mathrm{~cm}^{-1}$ for the 5'-end R-labeled (bottom) strand, $3.48 \times 10^{5} \mathrm{M}^{-1} \mathrm{~cm}^{-1}$ for the mid-Flabeled (top) strand and $3.68 \times 10^{5} \mathrm{M}^{-1} \mathrm{~cm}^{-1}$ for the 3'-end At-labeled (bottom) strand. Labeling efficiencies were determined by simultaneous absorbance measurements on Flabeled strands at $494 \mathrm{~nm}$ (molar extinction coefficient 75,000 M-1 $\mathrm{cm}^{-1}$ ); on R-labeled strands at $555 \mathrm{~nm}$ (molar extinction coefficient $91,000 \mathrm{M}^{-1} \mathrm{~cm}^{-1}$ ); and on At-stands at 560 $\mathrm{nm}$ (molar extinction coefficient 131,200 $\mathrm{M}^{-1} \mathrm{~cm}^{-1}$ ); extinction coefficients were obtained from Molecular Probes www.glenresearch.com/Technical/Extinctions.html). The percentage of labeled DNA in solution was estimated to be $>87 \%$ for all donor-labeled strands and $>95 \%$ for all acceptor-labeled strands.

Duplex DNA was formed by annealing complimentary oligomers of equimolar concentrations. The annealing buffer used was $20 \mathrm{mM}$ Tris-HCl, $\mathrm{pH} 8.0,1 \mathrm{mM}$ ethylenediaminetetraacetic acid (EDTA), and $200 \mathrm{mM} \mathrm{KCl}$. The mixture of oligomers was heated in a water bath at $90{ }^{\circ} \mathrm{C}$ for 10 minutes, then allowed to cool slowly at room temperature.

The IHF protein was prepared as described previously. ${ }^{59}$ Droplets of proteins were first flash-frozen in liquid nitrogen prior to storage in cryogenic tubes at $-80{ }^{\circ} \mathrm{C}$. Individual frozen droplets were diluted into the binding buffer, as needed. All measurements were performed in binding buffer: $20 \mathrm{mM}$ Tris- $\mathrm{HCl}(\mathrm{pH} 8.0), 1 \mathrm{mM}$ EDTA, $0.01 \% \mathrm{NP}-40$ with salt concentrations ranging from 100 to $300 \mathrm{mM} \mathrm{KCl}$. Protein concentrations reported in this 
study are effectively "active" protein concentrations, determined as described in SI Methods 1.1 .

All figures showing macromolecular structures were made using the PyMol molecular graphics system, version 2.0, Schrodinger, LLC.

\section{Steady-state fluorescence (acceptor ratio and anisotropy) measurements}

The steady-state fluorescence emission spectra and anisotropies were measured on a FluoroMax4 spectrofluorometer (Jobin Yvon, Inc., NJ, USA), with samples loaded in a 100$\mu \mathrm{L}$ quartz cuvette (Starna 26.100F-Q-10/Z20). Details of the acceptor ratio and anisotropy measurements are in SI Methods 1.2.

\section{Binding affinity measurements}

To determine the effect of the different labeled sequences on the IHF binding affinities, we performed equilibrium titration measurements for IHF and different DNA constructs at $20{ }^{\circ} \mathrm{C}$. These comparative binding affinity measurements were done at $300 \mathrm{mM} \mathrm{KCl}$, to bring the dissociation constants of the complexes $\left(K_{\mathrm{d}}\right)$ in the $>\mathrm{nM}$ range. At $100 \mathrm{mM} \mathrm{KCl}$, where most of the lifetime measurements were done, the $K_{\mathrm{d}}$ for the IHF-H' complex was previously found to be in the $\mathrm{pM}$ range, ${ }^{59-62}$ such that conventional titration experiments cannot measure these $K_{\mathrm{d}}$ values accurately. ${ }^{62}$ Details of the binding affinity measurements are in SI Methods 1.3.

\section{Fluorescence lifetime spectroscopy}

Fluorescence decay curves were measured with a PicoMaster fluorescence lifetime spectrometer (HORIBA-PTI, London, Ontario, Canada) equipped with time-correlated single photon counting (TSCPC) electronics. ${ }^{63}$ For all FRET measurements, decay traces were measured for donor-only duplexes without acceptor, denoted as DNA_D, as well as donor-acceptor-labeled duplexes, denoted as DNA_DA. The excitation source was a Fianium Whitelase Supercontinuum laser system (maximum power $4 \mathrm{~W}$ ), which produces 6 ps broad band pulses. For excitation of fluorescein, the laser pulses were passed through a monochromator set at $485 \mathrm{~nm}$ (bandpass $10 \mathrm{~nm}$ ) followed by a $488 \pm 10 \mathrm{~nm}$ bandpass filter. The emission from the sample was collected orthogonal to the excitation beam after passing through a $496 \mathrm{~nm}$ longpass filter (Semrock BrightLine FF01-496/LP-25), followed by another monochromator set at $520 \mathrm{~nm}$ (bandpass $10 \mathrm{~nm}$ ), and detected by a Hamamatsu microchannel plate photomultiplier (MCP-650). The instrument response function (IRF) of the system was measured using a dilute aqueous solution of Ludox (Sigma-Aldrich). The full width at half maximum (fwhm) of the IRF was $\sim 100$ ps. Fluorescence decay curves were recorded on a $100 \mathrm{~ns}$ timescale, resolved into 4096 channels, to a total of 10,000 counts in the peak channel, with the repetition rate of the laser adjusted to $10 \mathrm{MHz}$.

\section{Maximum entropy analysis of the fluorescence decay traces}

Fluorescence decay curves were analyzed using a maximum entropy method (MEM) in which the effective distribution of $\log$-lifetimes $f(\log \tau)$ was inferred from the decay traces using the program MemExp (available online), and described in detail elsewhere. ${ }^{64-65}$ The signal measured at time $t_{i}$ was fit by the expression: 


$$
\mathcal{F}_{i}=D_{0} \int_{-\infty}^{\infty} d \log \tau f(\log \tau) \int_{t_{0}}^{\min \left(t_{i}, t_{f}\right)} d t^{\prime} R\left(t^{\prime}+\delta\right) e^{-\left(t_{i}-t^{\prime}\right) / \tau}
$$

where $R$ is the measured instrument response function, $\delta$ is the zero-time shift and $D_{0}$ is a normalization constant. The instrument response is appreciable in the range $\left[t_{0}, t_{f}\right]$. The zero-time shift was determined using Brent's method of optimization ${ }^{66}$ and preliminary MEM calculations, each performed with $\delta$ fixed at a different value. A similar estimation of $\delta$ has been reported. ${ }^{67}$ The Poisson deviance between the fit and data was minimized while maximizing the entropy of the $f$ distribution.

The MEM inverts fluorescence decay traces into lifetime distributions without any a priori assumptions about the number of exponential terms. The MEM outputs of the donor-only samples gave single-peaked, narrow distributions, consistent with single-exponential decay. Fits to discrete exponential decays with two or more exponentials yielded less than $\sim 1 \%$ amplitude in the additional decay components (SI Figure S1).

The average FRET efficiencies measured on donor-acceptor labeled (DNA_DA) samples were computed from the MEM distributions as described in SI Methods 1.4. In the presence of the protein, lifetime decays on some DNA_DA samples yielded bimodal distributions, which were further analyzed in terms of two components, as described in SI Methods 1.4.

\section{RESULTS}

\section{Fluorescence lifetime measurements provide a snapshot of the distribution of bent conformations in IHF-DNA complexes}

In this study, we characterized the equilibrium distribution of DNA conformations when bound to IHF, by measuring the FRET efficiency between a donor-acceptor FRET pair attached to a 35-bp DNA substrate of varying sequences and binding affinities, using fluorescence lifetime studies. The FRET efficiency $(E)$ between the donor and acceptor labels depends strongly on the relative distance and orientation between the labels and can be computed from the lifetimes of the excited donor fluorophore in the presence $\left(\tau_{D A}\right)$ and absence $\left(\tau_{D}\right)$ of the acceptor, as $E=1-\frac{\tau_{D A}}{\tau_{D}}$. The measured FRET efficiencies can sense changes in the conformations of the DNA to which the labels are attached, for example upon binding of a DNA-bending protein. In the case of IHF-DNA complexes, FRET between labels attached at the ends of 35-mer DNA substrates has proven to be exceptionally useful in measuring not only equilibrium changes from unbent (straight) to bent conformations upon binding of IHF, ${ }^{68}$ but also the dynamics of these conformational changes along the recognition trajectory of the IHF binding site. $.59,62,69-70$

Here, we take advantage of the sub-nanosecond time-resolution of the fluorescence lifetime studies that enables fluorescence decays to be measured over a wide temporal range and with high temporal resolution. A single DNA conformation in the ensemble of molecules, with a well-defined separation and relative orientation between the donor and acceptor of the FRET pair, is characterized by a unique FRET efficiency, and is expected to yield one 
(faster) exponential decay for the donor fluorescence in the presence of the acceptor for every exponential decay observed in the absence of the acceptor. A distribution of DNA conformations corresponding to different donor-acceptor distance/orientations would then correspond to a distribution of FRET efficiencies, which should be reflected in a distribution of lifetimes measured in the decay traces. The lifetime distributions were obtained from the measured decay traces by the maximum entropy method (MEM).

The fluorescence lifetime of the donor (fluorescein), measured in DNA constructs in the absence of any acceptor (DNA_D), exhibited close to single-exponential decays with a relatively narrow distribution of lifetimes, and characterized by an effectively unique lifetime $\left\langle\tau_{D}>\approx 4.2-4.3 \mathrm{~ns}\right.$ that was found to be mostly insensitive to the position of attachment to the DNA or to the presence of the protein (SI Figure S1). In the presence of an acceptor fluorophore (DNA_DA), the decay profiles remained largely single-exponential with no protein bound (Figure 2), albeit with a shift in the donor lifetime $\left\langle\tau_{D A}\right\rangle$ relative to $\left\langle\tau_{D}\right\rangle$ if there was significant FRET (SI Figure S2). In contrast, for lifetime measurements on DNA_DA in the presence of IHF, not only did the donor lifetime shorten due to FRET, we also detected a broadening of the distribution of lifetimes and appearance of at least two distinct components (Figure 2 and SI Figure S3), which points to direct evidence for multiple DNA conformations in the IHF-bound complexes in the ensemble.

\section{IHF-H' complex reveals two dominant DNA conformations: fully-bent (high-FRET) and partially-bent/straight (low-FRET)}

We first present lifetime measurements carried out on the H' DNA substrate, end-labeled with fluorescein and TAMRA ( $\mathrm{H}^{\prime}$ in design I; Table 1), in the presence and absence of IHF. The design of this construct is identical to what we and others have used in previous equilibrium and kinetics studies on IHF-DNA complexes. ${ }^{61,69}$ All lifetime measurements were done with $5 \mu \mathrm{M}$ DNA and $5 \mu \mathrm{M}$ IHF. At $100 \mathrm{mM} \mathrm{KCl}$, the average FRET efficiency in the H' DNA construct alone was found to be $0.022 \pm 0.001$, which increased to 0.50 \pm 0.03 upon binding of IHF under 1:1 binding conditions. These FRET efficiency values are consistent with steady-state values reported previously for these constructs, ${ }^{61,69-70}$ and reflect the decrease in the end-to-end distance when H' DNA is bent into a U-turn in the complex, as illustrated in the crystal structure of the IHF-H' complex (Figure 1).

MEM analysis on the double-labeled IHF-H' fluorescence decay traces revealed two dominant lifetime populations for these constructs, with $78 \pm 3 \%$ of the population in a high FRET state $(0.65 \pm 0.03)$, and $22 \pm 3 \%$ in a low FRET state $(0.085 \pm 0.002)$. We note here that the low FRET state is close to what we observe in unbound (straight) DNA, and could arise from (i) a fraction of DNA that is unbound or (ii) a fraction that is nonspecifically bound and that competes with specific binding or (iii) a fraction that is specifically bound but only partially bent, for example if the energetic cost of kinking at two sites is not fully compensated for by stabilizing interactions between protein and bent DNA. Other contributions to this low-FRET state could be from potential artifacts, such as incompletely labeled (or incompletely annealed) DNA with some fraction of donor-only labeled DNA molecules lacking an acceptor, or partial stacking of the fluorophores at the ends of the DNA that could result in different dye orientations (stacked or unstacked) and hence two or more 
distinct FRET states. We ruled out any significant contributions to the observed lifetime distributions from these artifacts, as described in SI Results and SI Figure S2.

The low-FRET population does not reflect unbound DNA under the 1:1 binding conditions

We first address whether the low-FRET population could have contributions from a significant fraction of unbound DNA, even in our 1:1 binding conditions. We note that under buffer and salt conditions (100 $\mathrm{mM} \mathrm{KCl)} \mathrm{identical} \mathrm{to} \mathrm{those} \mathrm{used} \mathrm{for} \mathrm{these} \mathrm{measurements,}$ the $K_{\mathrm{d}}$ of the IHF-H' complex was previously determined to be $25 \mathrm{pM}$, from stoppedflow measurements, ${ }^{61}$ and $27 \mathrm{pM}$, from equilibrium salt-titration measurements. ${ }^{59}$ The binding studies on IHF-H' presented here are consistent with the previous studies, with an extrapolated value of $K_{\mathrm{d}} \approx 23 \mathrm{pM}$ at $100 \mathrm{mM} \mathrm{KCl}$ (SI Figure S4 and SI Figure S5). Therefore, at the protein and DNA concentrations used for the lifetime studies ( $5 \mu \mathrm{M}$ each) we expect to have $>99.8 \%$ of the DNA in complex.

To confirm 1:1 binding conditions for these complexes, we carried out equilibrium titration measurements at a fixed $(1 \mu \mathrm{M})$ concentration of H'_DA DNA and varying concentrations of IHF, and simultaneously measured both the acceptor ratio (to measure the extent of bent DNA), and donor anisotropy (to measure the extent of protein binding). These data, shown in Figure 3A-B, exhibited behavior that deviated from what is expected for a 1:1 binding isotherm. The acceptor ratio initially increased with increasing protein concentration, as anticipated, and reached a maximum value at $[\mathrm{IHF}]:\left[\mathrm{H}^{\prime}\right] \approx 1: 1$; however, the acceptor ratio began to drop with further excess of protein. In contrast, the anisotropy also initially increased with increasing protein concentration, but then continued to increase with further excess of protein beyond [IHF]:[H'] $\approx 1: 1$. Taken together, we draw the following conclusions from these data: at $[\mathrm{IHF}]:\left[\mathrm{H}^{\prime}\right] \approx 1: 1$, each DNA molecule is bound to a single copy of IHF in a specific complex; below this concentration ratio, there is a mixture of unbound and specifically-bound DNA; above this ratio, there is competition between specific and nonspecific binding, with increasing protein concentrations tilting the equilibrium in favor of a nonspecific binding mode in which more than one copy of IHF is bound to a single 35-mer, resulting in higher molecular weight complexes containing less bent DNA (Figure 3C). Competition between specific and nonspecific binding at high IHF to DNA concentrations has been well documented in previous studies. ${ }^{51,71-72}$

\section{Increasing the salt concentration diminishes contributions from nonspecific binding}

To further examine this competition between specific and nonspecific binding, we performed measurements at a higher salt concentration, $200 \mathrm{mM} \mathrm{KCl} \mathrm{(Figure} 3$ and SI Figure S6). Equilibrium studies on the ionic strength dependence of protein-DNA complexes have shown that while higher ionic strength conditions disfavor both binding modes, such conditions are typically more disruptive to nonspecific than to specific binding. ${ }^{51,73-77}$ In other words, an increase in salt is expected to shift the equilibrium in favor of specific binding, as has indeed been demonstrated by isothermal titration calorimetry (ITC) studies for IHF-H ${ }^{51}$ as well as for other DNA-bending proteins. ${ }^{78-81}$ This behavior reflects the fact that nonspecific interactions are primarily electrostatic interactions between the protein and the DNA phosphate groups, while specific interactions have significant contributions from hydrogen bonds, van der Waals interactions, and water-mediated interactions that are 
less affected by ionic strength. Therefore, by increasing the salt concentration from 100 to $200 \mathrm{mM} \mathrm{KCl}$, we anticipated that the contributions from nonspecific binding in our IHF-H' complexes should diminish, even when IHF is present in excess over DNA.

We repeated our equilibrium titration measurements in $200 \mathrm{mM} \mathrm{KCl}$ conditions, with acceptor ratio and anisotropy as probes of the binding process, as before (Figure 3D-E). Indeed, unlike the $100 \mathrm{mM} \mathrm{KCl}$ data, the acceptor ratio versus protein concentration profile in $200 \mathrm{mM} \mathrm{KCl}$ exhibited the behavior expected for a 1:1 binding isotherm, with the acceptor ratio initially increasing with protein concentration, and then reaching a plateau with protein in excess. The anisotropy data also resembled a 1:1 binding isotherm and did not show any significant evidence for multiple protein binding. Taken together, we infer that at $200 \mathrm{mM} \mathrm{KCl}$ nonspecific binding is sufficiently destabilized such that we observe only specific binding at all protein:DNA concentrations.

We now return to the question: what is the origin of the low-FRET component in the lifetime distributions measured on IHF-H' in $100 \mathrm{mM} \mathrm{KCl}$ under 1:1 conditions? Corresponding lifetime measurements for the $1: 1$ complex at $200 \mathrm{mM} \mathrm{KCl}$ also showed two populations in the lifetime distributions (Figure 3F), with $66 \pm 2 \%$ in the high FRET state $(E \approx 0.67$ $\pm 0.02)$ and $34 \pm 2 \%$ in the low FRET state $(E \approx 0.043 \pm 0.001)$. Even with a 2.5 -fold increase in the protein concentration (2.5:1 complex) in $200 \mathrm{mM} \mathrm{KCl}$, almost no change was observed in the IHF-H' lifetime distribution, consistent with our acceptor ratio and anisotropy data at $200 \mathrm{mM}$ that showed no evidence for nonspecific binding at excess protein conditions. From these data we conclude that the low-FRET state must be a less-bent DNA conformation of a specifically-bound complex, and which could not be detected in previous steady-state measurements or in crystal structures. The population in this less-bent conformation increased from $\sim 22 \%$ to $\sim 34 \%$ with the increase in salt concentration from 100 to $200 \mathrm{mM} \mathrm{KCl}$.

\section{Measurements with different placement of FRET labels (design II constructs) implicate the low-FRET state as arising from conformations with less bent DNA}

The results presented thus far are insufficient to conclude whether the low-FRET component was from specifically-bound but straight DNA or from an ensemble of partially bent conformations, for example with DNA kinked at only one site or the other. With the FRET labels attached at the ends of the 35-mer H' substrate (design I in Table 1), the end-to-end distance for a straight piece of DNA is estimated to be $\sim 121 \AA$ (SI Figure S7), with near zero FRET efficiency, assuming Forster distance $R R_{0} \approx 50 \AA$ for this FRET pair. ${ }^{68,82}$ If we envision a distribution of partially bent conformations with either one side kinked or the other, as illustrated in SI Figure S7, then the end-to-end distance is estimated to be $\sim 90$ $\AA$, with FRET $E \approx 0.03$. We note that these FRET estimates, especially for the partially bent conformations, are only rough approximations based on reasonable guesses of these structures and the expected distances between the atoms where the labels are attached. Furthermore, these FRET estimates do not account for linker lengths used to attach the labels or their dynamics. Despite these caveats, these estimates are in reasonably good agreement with $\mathrm{E} \approx 0.083 \pm 0.002$ measured for the low-FRET state in IHF-H' at $100 \mathrm{mM}$ $\mathrm{KCl}$. However, the width in our lifetime distributions makes it difficult to unambiguously 
separate these low-FRET states from those obtained on straight DNA (Figure 2). To increase the sensitivity of our FRET measurements and more clearly detect FRET changes between straight and partially bent conformations as envisioned above, we altered the labeling strategy to design II (see Table 1 and SI Figure S7), in which the labels are placed closer together along the DNA. In these constructs, we attached the donor (fluorescein) internally, at a thymine located at position 26 of the top strand (counting from the 5' end), and attached Atto550 (At) at the 3' end of the bottom strand. The separation between the attachment points of the labels in these design II constructs is $\sim 86 \AA$ in unbent DNA (SI Figure S7).

Fluorescence lifetime decay traces on donor-only H' DNA in the design II constructs, performed at $100 \mathrm{mM} \mathrm{KCl}$ conditions, still exhibited a predominantly single-exponential decay, both in the absence and presence of IHF (Figure 4 and SI Figure S1). The lifetime decay traces for donor-acceptor-labeled H'_DA remained primarily single-exponential, with FRET $E$ of $0.113 \pm 0.002$. In the presence of IHF, the lifetime distributions on the doublelabeled constructs showed two distinct FRET states, with a high-FRET state observed at $0.51 \pm 0.01$ and a low-FRET state at $0.29 \pm 0.01$, reaffirming our results from design I that the DNA in this ensemble samples different conformations. More important, in the design II constructs, the FRET efficiency of the low-FRET component in the IHF-DNA complex is well separated from the FRET efficiency of unbound DNA, supporting the conclusion that the low-FRET state corresponds to partially bent DNA. These partially bent complexes could be a mixture of conformations with one side kinked or the other, as explained below, while the high-FRET state likely corresponds to both DNA sites being kinked and the flanking arms of the DNA held against the sides of the protein, as seen in the crystal structures.

We note here that while the FRET values measured in the two constructs (design I and II) cannot be quantitatively compared because the FRET pairs used in these constructs are different and may not have the same Forster distance, our observation that the high-FRET component shifts to lower FRET values while the low-FRET component shifts to higher FRET values when we change from design I to design II is not inconsistent with what we anticipated. Although the separation between the labels is shorter along the DNA in design II, the labels in design I are in fact spatially closer than in design II in the fully-bent state, as illustrated in SI Figure S7; in the partially bent states, the labels in design I are expected to be further away than in design II. We also note that the population distribution between the high- and low-FRET states in the design II constructs are split more evenly, with $\sim 50 \%$ in each of these conformations, compared with the approximately $80 \%$ versus $20 \%$ split observed for the complex in the design I construct under identical conditions. The reason for this population shift could be some steric hindrance between the internally located fluorescein label on the DNA near one of the kink sites that could hamper IHF from keeping the flanking arm of the DNA against its side, although the binding affinity measurements at $300 \mathrm{mM} \mathrm{KCl}$ showed no significant difference in the $K_{\mathrm{d}}$ values for IHF-H' between the two designs (see Table 1). The remaining results presented below are for the design I constructs. 


\section{The $\mathrm{H} 1$ site, which lacks the A-tract, favors the less bent state}

We next examined the conformational distribution of another specific binding site recognized by IHF, the $\mathrm{H} 1$ site on phage lambda DNA. H1 has the same consensus region as H' (the WATCAAnnnnTTR indicated in gray in Table 1) but differs primarily in the other half of the binding site where it lacks the A-tract that is present in the H' sequence. Previous stopped-flow measurements revealed a $K_{\mathrm{d}}$ of $\sim 20 \mathrm{pM}$ for the IHF-H1 complex at $100 \mathrm{mM}$ $\mathrm{KCl},{ }^{60}$ very similar to the $K_{\mathrm{d}}$ from stopped-flow on the IHF-H' complex. ${ }^{60-61}$ These results indicate that the lack of the A-tract appears to be compensated for by other changes in the $\mathrm{H} 1$ sequence compared with $\mathrm{H}$ ' so as not to significantly perturb the overall binding affinity. However, the average FRET efficiencies measured for the two end-labeled (design I) constructs in complex with IHF are distinctly different. Our lifetime studies (performed at $100 \mathrm{mM} \mathrm{KCl}$ and $20{ }^{\circ} \mathrm{C}$ ) revealed an average FRET efficiency of $0.25 \pm 0.01$ for the IHF-H1 complex compared with $0.50 \pm 0.03$ for IHF-H' complex (Table 1), consistent with previous steady-state measurements on these complexes using identical constructs and buffer conditions. ${ }^{60-61,69}$ The decreased FRET efficiency measured in the IHF-H1 complex suggests an inability of IHF to keep the bent arm of the DNA by its side in the absence of the A-tract.

To examine how the absence of the A-tract affects the relative populations of differently bent DNA conformations, we analyzed the fluorescence decay traces measured on the endlabeled IHF-H1 complex with the MEM, as before. The lifetime distributions for IHF-H1 also show two peaks (Figure 5 and SI Figure S3); however, the DNA in the IHF-H1 complex prefers the low-FRET conformation, with only $32 \pm 1 \%$ in the high FRET state $(E \approx 0.50 \pm$ $0.03)$ and a larger fraction, $68 \pm 2 \%$, in the low FRET conformation $(E \approx 0.14 \pm 0.01)$. We assert that these remarkable differences in the conformational distributions of IHF-H' and IHF-H1 are primarily from the presence and absence of the A-tract, although there are some other changes in the two sequences, especially at the kink sites (see Table 1), that could also be affecting the distributions and the binding affinities. For example, we note that even the high FRET conformation in IHF-H1 (FRET $E \approx 0.50$ ) appears to be not as fully bent as in IHF-H' (FRET $E \approx 0.65$ ).

To further examine the differences that arise purely from the presence or absence of the A-tract, we also conducted experiments on a modified H' construct, denoted as H'_nAt, which differs from the $\mathrm{H}^{\prime}$ construct only in the A-tract segment, which was swapped by the corresponding segment in the H1 site (see Table 1). Binding affinity measurements with end-labeled H'_nAt showed a $~ 2$-fold increase in $K_{\mathrm{d}}$ compared with H' (measured at 300 $\mathrm{mM} \mathrm{KCl}$; SI Figure S5 and Table 1). The distribution of FRET components in IHF-H'_nAt mirrored that observed in IHF-H1, with a lower fraction (33 $\pm 1 \%)$ in the high-FRET state $(E \approx 0.57 \pm 0.03)$ and a larger fraction $(67 \pm 1)$ in the low-FRET state $(E \approx 0.077 \pm$ 0.002) compared with IHF-H'. These results highlight the importance of the A-tract and the contacts that it facilitates with IHF to help the protein clamp the bent arm of the DNA on that side. The binding preference of IHF for the A-tract was well noted when the crystal structure was solved, since the A-tract has a unique structure with a narrow minor groove and a high twist which allows it to fit into the protein clamp without significant additional distortions. ${ }^{9}$ 


\section{Insertion of a mismatch at a kink site in $\mathrm{H} 1$ on the A-tract side helps recover the U-bent conformation}

Next, we inserted a 4 nucleotide "bubble" (CT/TC mismatch) into the H1 sequence at the kink site on the same side as where the A-tract is in H' (see H1_CTloop in Table 1). The 4-nt mismatch bubble is expected to enhance the "kinkability" of the $\mathrm{H} 1$ sequence on that side and increase the IHF binding affinity, as was shown previously for similar mismatched sequences in the H' context. ${ }^{56,59,70}$ Binding affinity measurements with end-labeled H1_CTloop showed a $\sim 125$-fold decrease in $K_{\mathrm{d}}$ compared with matched H1 (measured at $300 \mathrm{mM} \mathrm{KCl}$; SI Figure S5 and Table 1), a result consistent with previous $K_{\mathrm{d}}$ measurements on H' sequence with a TT/TT mismatch introduced at the same kink site. ${ }^{56,59,70} \mathrm{We}$ anticipated that the insertion of the mismatch in $\mathrm{H} 1$ to lower the energetic penalty for kinking should help compensate for the lack of stabilizing interactions afforded by the A-tract. In other words, we expected to recover some of the lost high FRET state in IHF-H1 in the presence of the mismatch. Our lifetime studies are consistent with this expectation.

First, the average FRET efficiency measured in IHF-H1 increased from $0.25 \pm 0.01$ in the matched construct to $0.36 \pm 0.02$ in the mismatched (H1_CTloop) construct (Figure 6 and SI Figure S3). Second, the population in the high-FRET component increased from $32 \pm 1 \%$ in the matched IHF-H1 to $43 \pm 3 \%$ in IHF-HI_CTloop. In addition, we observed a shift in the FRET efficiency values for the two populations, with the high FRET state shifted from $0.50 \pm 0.03$ to $0.55 \pm 0.02$, and the low-FRET state shifted from $0.14 \pm 0.01$ to $0.25 \pm 0.01$, when comparing matched versus mismatched versions of this complex. These shifts in the FRET efficiencies indicate additional conformational changes in the kinked/straight states of the DNA introduced by the mismatched bubble.

\section{A destabilizing modification in the TTG consensus region of $H^{\prime}$ increases the population in (another) low-FRET state}

Next, we examined the effect of sequence modifications in the TTR consensus region on the other flanking arm of the DNA (Figure 1). In this consensus site, a single adenine substitution (TTG $\rightarrow$ TAG) as shown in the sequence H'44A (Table 1), was found to destabilize the binding affinity of IHF by about 100 - to 250 -fold. ${ }^{57,59}$ The crystal structure for the IHF-H'44A complex revealed that this single nucleotide substitution inhibited the twisting of the DNA that was needed to form a network of salt bridges with IHF that stabilized the bent DNA conformation against that side of the protein. ${ }^{57}$ However, the crystal structure of IHF-H'44A did reveal a fully bent conformation very similar to that of IHF-H'. In contrast, steady-state FRET measurements on the IHF-H'44A complex at $20{ }^{\circ} \mathrm{C}$ in solution yielded a smaller average FRET efficiency than IHF-H' for the design I constructs under identical binding conditions, ${ }^{59}$ indicating some degree of "floppiness" in the bent conformations of IHF-H'44A.

To examine how this $\mathrm{T} \rightarrow \mathrm{A}$ mutation in the TTG region affects the populations in the fully versus partially bent conformations of the IHF-bound specific complexes, we carried out lifetime studies on the end-labeled (design I) IHF-H'44A complex (Figure 7 and SI Figure S3). We still observe two populations as for the IHF-H' complex, with a high 
FRET state at $E \approx 0.62 \pm 0.02$ and a low FRET state at $E \approx 0.076 \pm 0.001$, but with a significant decrease in the high FRET population of $32 \pm 1 \%$ compared with $\sim 78 \%$ in IHF-H'. These results demonstrate the importance of the TTG consensus region in keeping that side of the DNA clamped against the protein and further show that neither of the flanking DNA arms are held rigidly in place. Taken altogether, we conclude that although only two distinct FRET populations are discerned in the MEM lifetime distributions, the combined results from IHF-H', IHF-H'_nAt, and IHF-H'44A strongly suggest that at least three conformations co-exist in solution for a specifically bound protein complex: a fully bent conformation reflected in the high-FRET component and at least two partially bent conformations with one arm straight or the other, with overlapping FRET levels that are not distinguishable in the low-FRET component (SI Figure S7). The results from IHF-H'44A suggest that the population in the low-FRET state increased from $22 \%$ to $68 \%$ as a result of increased population in the second partially bent conformation that affects the TTG side of the complex when that side was compromised.

\section{DISCUSSION}

IHF is a small protein belonging to a class of nucleoid-associated DNA-bending proteins. Apart from its nonspecific biological function in condensing the bacterial nucleoid, it also binds in a sequence-specific manner and serves as an architectural factor in many cellular activities such as site-specific recombination, DNA replication and transcription. ${ }^{83-84}$ The ability of IHF to bend the DNA containing its specific site into a U-turn by wrapping $~ 35$-bp DNA around three sides of the protein has earned it the moniker of the "master bender". 85 Remarkably, IHF accomplishes this feat with almost no direct interactions between the protein residues and specific bases, and has thus become an excellent model system for studies of sequence-dependent DNA shape and deformability that underpins binding site recognition by indirect readout. ${ }^{72,86-88}$

The sharp DNA bends induced by IHF allow for FRET measurements to be sensitive reporters of the extent of DNA bending. Previous studies took advantage of timeresolved FRET to investigate DNA-bending kinetics in IHF-DNA complexes, ${ }^{61,69}$ which demonstrated the stepwise binding-then-bending mechanism for site recognition by IHF. ${ }^{89}$ Further kinetics studies resolved a two-step "interrogation-then-recognition" process: nonspecific interrogation on $\sim 100-500 \mu$ s timescale prior to recognition on 1-10 ms timescale. ${ }^{70}$ However, these "ensemble" approaches could only provide an average picture of the dynamics along the reaction trajectory. What remained elusive was whether multiple conformations of the complex could co-exist in solution, as was recently shown for damaged DNA specifically bound to NER damage-recognition protein XPC/Rad4. ${ }^{43}$ Here, we investigated the distribution of bent conformations in IHF-DNA complexes with varying DNA sequence composition and binding affinities. We utilized fluorescence lifetime decay measurements and the maximum entropy method (MEM) to infer multiple FRET efficiencies that enabled us to visualize and quantitatively characterize the heterogeneity of bent conformations.

Like many DNA-bending proteins that kink DNA at localized sites, IHF concentrates the U-shaped bend in two sharp kinks separated by $9 \mathrm{bp}$. At the kink sites, a single base step is 
unstacked and opened towards the minor groove of the DNA, and stabilized by intercalation of conserved proline residues on the $\beta$-arms of the protein that wrap around the DNA. The flanking sides of the DNA on the outer sides of the kinks are held against the body of the protein through a myriad of specific and nonspecific interactions. Notably, the consensus DNA-binding motif consists of only a 6-bp stretch (WATCAR) in between the kink sites and another 3-bp stretch (TTR) in the flanking DNA, making it all the more remarkable that IHF is able to overcome the energy penalty needed to severely deform the DNA at its preferred sites and bind with affinities that can exceed $10^{3}-10^{4}$-fold compared with random sequences. ${ }^{90-93}$

How accurate is this picture of bent DNA rigidly held against the protein, as implied by the static crystal structure of the IHF-H' complex? Incorporation into a crystal can "freeze out" macromolecular dynamics and will tend to select a single conformation from the ensemble that may exist in solution. The results reported here demonstrate that IHF does in fact experience some difficulty in keeping the bent arms of the DNA at its side. For the IHF-H' complex in $100 \mathrm{mM} \mathrm{KCl}$, the ensemble of bent conformations appears as two discernible populations, as inferred from the distribution of lifetimes recovered for labeled DNA constructs. For the end-labeled (design I) constructs, the population in the fully-bent high-FRET state $(E \approx 0.65$ ) is found to be $78 \%$, with the remaining $22 \%$ in a low-FRET state $(E \approx 0.085)$. Although measurements on the design I constructs could not readily distinguish between partially bent or unbent DNA, FRET measurements with design II constructs, where the FRET labels are placed closer together along the DNA, establish that the low-FRET state is not from unbent (straight) DNA. The low-FRET state is attributed to a partially bent but still specific complex, as clarified from measurements at $200 \mathrm{mM}$ $\mathrm{KCl}$, where nonspecific binding is disfavored, and yet the amplitude of the low-FRET state increases. From these and further results discussed below, we assign the low-FRET state to an ensemble of specifically-bound conformations with either one or the other kink site unkinked (Figure 8). The free energy of the fully bent IHF-H' conformation is estimated to be $1.3 \mathrm{k}_{\mathrm{B}} T$ lower than the partially bent ensemble in $100 \mathrm{mM} \mathrm{KCl}$ and $0.7 \mathrm{k}_{\mathrm{B}} T$ lower in $200 \mathrm{mM} \mathrm{KCl}$ (Table 2). Notably, the FRET efficiency levels observed in the fully-bent conformation are very similar in both ionic conditions.

This tug-o-war between protein-induced DNA kinking and the propensity of DNA to retain an unkinked conformation is further illustrated by measurements with the $\mathrm{H} 1$ binding site that is missing an A-tract found in the H' site, which is known to help stabilize the bent DNA conformation in the IHF-H' complex. ${ }^{9}, 50$ FRET efficiencies obtained for IHF-H1 revealed significantly less population $(32 \%)$ in the high-FRET conformation, indicating that the free energy of the fully-bent IHF-H1 conformation is $0.8 k_{\mathrm{B}} T$ higher than the partially bent conformations. Furthermore, the protein-DNA interactions in the fully bent IHF-H1 conformation (FRET $E \approx 0.50$ ) appeared to be looser than that in the fully-bent IHF-H' (FRET $E \approx 0.65$ ). Similar results were obtained on complexes with a modified H' construct (H'_nAt) that was also lacking the A-tract. Insertion of 2-bp mismatches at one of the kink sites in $\mathrm{H} 1$ close to the side that was missing the A-tract (H1_CTloop in Table 1), designed to make the DNA more "kinkable", compensated to some extent for the loss of the A-tract; the fully-bent complex in IHF-H1_CTloop was still less favored but now only by $0.3 k_{\mathrm{B}} T$ (Table 2). Thus, the A-tract helps to maintain a tight fit in the complex and its loss results in 
significant unkinking on that side. These results are in accord with previous hydroxyl radical footprinting studies that showed less protection in that patch in sequences that were missing the A-tract. ${ }^{46,86}$

Another important and highly conserved feature common to all known binding sites of IHF is the TTR consensus region on the other flanking side of the DNA. Previous studies identified that a $\mathrm{T} \rightarrow \mathrm{A}$ switch at the center position of the TTR element (H'44A) resulted in >100-fold decrease in binding affinity for IHF. ${ }^{57,} 59,94$ Comparison of IHF-H' and IHF-H'44A structures showed that the ability of the TTR site to adopt an unusually highly twisted conformation at the Y-R step when bound to IHF was necessary to facilitate stabilizing salt bridges between key residues of IHF. ${ }^{57}$ These studies exemplified how sequence-dependent DNA deformability was critical to the recognition of that consensus site.

The crystal structures of IHF-H' and IHF-H'44A were otherwise very similar, with approximately the same overall bend in the DNA observed in both structures. ${ }^{57}$ In contrast, previous steady-state FRET studies that monitored the average end-to-end distance already revealed a less bent conformation for IHF-H'44A in solution, with FRET efficiency levels nearly half of what was observed in IHF-H'. ${ }^{59}$ Our lifetime measurements directly show that indeed the fraction in the fully-bent conformation of IHF-H' $44 \mathrm{~A}$ is only $32 \%$, indicating a penalty $(\Delta \Delta G)$ of about $2 \mathrm{k}_{\mathrm{B}} T$ between the bent and unbent states that is attributable to the loss of the salt bridge interactions at the TTR site.

It is informative to compare the conformational distributions characterized here for the specific IHF-DNA complexes with the conformational distributions for the structurally similar but nonspecific $\mathrm{HU}$ protein observed in AFM studies. ${ }^{25} \mathrm{HU}$ is known to bind in a sequence-independent manner to DNA with $K_{\mathrm{d}}$ values that range from $200 \mathrm{nM}$ to $2.5 \mu \mathrm{M},{ }^{24,}, 95$ and with much higher affinities to distorted DNA. ${ }^{55,95-96}$ Single-molecule micromanipulation studies of HU-bound DNA showed that at low HU/high monovalent salt concentrations, HU dimers induce very flexible bends that result in DNA compaction and a dramatic decrease in the apparent persistence length of DNA compared with bare DNA. ${ }^{25,97}$ AFM studies under similar conditions revealed a very broad range of bend angles in the DNA at the sites where $\mathrm{HU}$ was bound, ${ }^{25}$ with a nearly uniform distribution of angles from $0^{\circ}$ (unbent) to $180^{\circ}$ (bent into a $\mathrm{U}$-shape). Together, these studies revealed a highly compliant and very flexible HU-DNA complex.

Similar conclusions were drawn from force-extension measurements on long DNA with IHF bound nonspecifically that also showed enhanced apparent DNA flexibility with the bound proteins. ${ }^{93,} 98$ AFM studies with specific IHF-DNA complexes revealed single broad distributions peaked at bending angles of $\sim 120-130^{\circ}$, with a range that covered bending angles from $\sim 80^{\circ}$ to $\sim 160^{\circ} .{ }^{27,33}$ These AFM studies were done with other IHF-DNA complexes; we are unaware of similar studies with IHF-H'. Notably, the range of bent conformations observed in AFM covers what we expect for the low-FRET state (with one site kinked) and for the high-FRET state (with both sites kinked). 
However, our studies indicate a somewhat "brittle" complex for IHF bound to its specific site. Rather than describing a broad and continuous range of bent conformations as seen in AFM images of HU-DNA and IHF-DNA complexes, our data support two or likely three preferred conformations, with the populations among these distinct valleys in the free energy landscape modulated by the DNA sequence. While only two distinct FRET states could be discerned in our lifetime distributions on all the complexes, the relative populations in these so-called low- and high-FRET states could be modulated by making modifications in the DNA flanking segments on either side, whether in the A-tract segment on one side or the TTR consensus segment on the other side, with destabilizing modifications on either side resulting in an increase in the low-FRET population at the expense of the high-FRET population. These observations suggested that the low-FRET component likely included contributions from two subpopulations, with either one arm unbent or the other, that had very similar FRET levels and therefore were not distinguishable as two distinct peaks in our lifetime distributions.

In a previous smFRET study on IHF-H' that used a 55-bp DNA construct containing the H' site and end-labeled with a FRET pair, ${ }^{99}$ a bimodal FRET distribution was indeed observed, with $\sim 85 \%$ in a high-FRET conformation consistent with the crystal structure and 15\% population in what appeared as a "zero-FRET" conformation. Remarkably, a very similar bimodal distribution was also observed in complexes of $\mathrm{HU}$ bound to a 55-mer with two TT mismatches 9 bp apart, but not with HU bound to the 55-mer H' construct, which revealed a broad, feature-less distribution reflecting less severely bent conformations. HU has been shown to bind with very high affinity ( $K_{\mathrm{d}}$ in the $4-10 \mathrm{pM}$ range) to DNA substrates with mismatches spaced 9 bp apart and it is not unexpected that $\mathrm{HU}$ can induce U-bends in these high affinity sequences similar to IHF-H'. The authors of this study interpreted the zero-FRET component as arising from nonspecifically bound proteins. Indeed, it is not evident that these smFRET measurements could discern distinct populations within the specific complex, if those conformations interconverted on timescales faster than (or comparable to) the 1 ms binning times of this smFRET study. ${ }^{99}$ Kinetics measurements on IHF-DNA complexes indicate that DNA bending/unbending dynamics within the complex are indeed fast, on micro-to-millisecond timescale. ${ }^{59,61,69-70}$

Another smFRET study, ${ }^{100}$ designed to examine rigid versus flexible kinks for another nonspecific DNA-bending protein from the eukaryotic family of HMG box proteins, concluded that the $\sim 60^{\circ}$ kinks induced by that protein appeared to be rigid kinks, with the apparent enhancement of DNA flexibility induced by these proteins attributed to binding/ unbinding of the protein to induce random and transient kinks. Again, as the authors of that study noted, the $\sim 30 \mathrm{~ms}$ binning time of their smFRET measurements could have averaged out any dynamic flexibility. Further studies, including measurements of the kind reported here, are needed to carefully flesh out the dynamics and distributions of these ubiquitous DNA benders. ${ }^{101}$

Our observation of partially bent specific conformations in IHF-DNA complexes also provides structural insights into the underlying mechanism for the "facilitated dissociation" observed for several protein-DNA complexes, whereby dissociation rates of these complexes are found to depend on the protein concentrations. ${ }^{102-106}$ As postulated by 
others, ${ }^{105}, 107-108$ for dimeric DNA-binding proteins, the release of a monomer from a halfsite is a plausible mechanism to generate a partially bound intermediate, thereby making room for another protein to bind and eventually displace the first protein. Our measurements provide direct evidence for analogous partially bound structures in IHF-DNA complexes, in which the unkinked DNA arm could interact with a second IHF dimer before the first one fully dissociates.

Finally, we propose that the details of IHF binding sites have evolved to fit their biological roles (Figure 9). In particular, the A-tract that clearly helps to keep the DNA bent in the U-shape is not conserved across the many known IHF sites, $\mathrm{H} 1$ being a case in point. Binding of IHF to both the H' and H1 sites is required for integration of phage lambda into the $E$. coli chromosome to establish lysogeny. The $\mathrm{H}^{\prime}$ and $\mathrm{H} 1$ sites are found within the "attP" region of phage lambda, which is bound synergistically by 3 copies of IHF and 4 copies of lambda integrase to form a large complex (termed an intasome) that then binds the bacterial insertion site ("attB") and catalyzes a site-specific recombination reaction between attP and attB that results in the integration of the phage DNA into that of the host. Modeling of this intasome shows that, while the IHF-H' complex might need to flex slightly to allow synergetic binding of two domains of integrase to DNA sequences flanking it, it can remain static throughout the integration reaction. ${ }^{58}$ However, in the fully bent form of the IHF-H1 complex, the flanking DNA and the copy of integrase bound to it block incorporation of the bacterial attB DNA segment. Significant flexing of the H1-induced DNA bend as shown in Figure 9 is therefore required for its biological function.

\section{CONCLUSION}

The present study showcases the power of combining fluorescence lifetime measurements with MEM analysis for investigating conformational flexibility in protein-DNA complexes and establishes conclusively that IHF bound to its specific sites samples two or more distinct conformations. These conformations include a fully-bent conformation such as that observed in the crystal structures of IHF-DNA and competing conformations in which very likely either one kink site or the other is unkinked. The equilibrium distribution between these different conformations depends sensitively on DNA sequence, especially the A-tract on one side of the U-bend and the TTR consensus site on the other side. The "kinkability" at the kink sites also has a measurable effect on the distribution. Further studies of this nature would be very useful in characterizing DNA sequences that render DNA highly "kinkable" and data such as these could be used to further refine models for sequencedependent DNA deformability and protein-DNA interactions needed to stabilize distorted DNA conformations in complex with DNA-bending proteins.

\section{Supplementary Material}

Refer to Web version on PubMed Central for supplementary material.

\section{Acknowledgments}

A.A. acknowledges Bill Eaton for many discussions on protein dynamics over the years. We thank Ying Z. Pigli for the purification of IHF proteins and Greg Van Duyne for kindly providing the coordinates for the integrative 
intasome model. We also thank Jacob Bathery and Rafid Rahman for their help with equilibrium measurements. This work was funded by National Science Foundation (NSF) grants MCB-1715649 (to A.A. and P.A.R.) and an LAS Award for Faculty in the Sciences from the University of Illinois at Chicago (to A.A.) This work was also supported by the Intramural Research Program of the National Institutes of Health (NIH, CIT).

\section{References}

1. Crick FH; Klug A. Kinky helix. Nature 1975, 255, 530-533. [PubMed: 1095931]

2. Luger K; Mader AW; Richmond RK; Sargent DF; Richmond TJ Crystal structure of the nucleosome core particle at 2.8 A resolution. Nature 1997, 389, 251-260. [PubMed: 9305837]

3. Hogan ME; Rooney TF; Austin RH Evidence for kinks in DNA folding in the nucleosome. Nature 1987, 328, 554-557. [PubMed: 2441260]

4. Richmond TJ; Davey CA The structure of DNA in the nucleosome core. Nature 2003, 423, 145150. [PubMed: 12736678]

5. Love JJ; Li X; Case DA; Giese K; Grosschedl R; Wright PE Structural basis for DNA bending by the architectural transcription factor LEF-1. Nature 1995, 376, 791-795. [PubMed: 7651541]

6. Schultz SC; Shields GC; Steitz TA Crystal structure of a CAP-DNA complex: the DNA is bent by 90 degrees. Science 1991, 253, 1001-1007. [PubMed: 1653449]

7. Kim JL; Nikolov DB; Burley SK Co-crystal structure of TBP recognizing the minor groove of a TATA element. Nature 1993, 365, 520-527. [PubMed: 8413605]

8. Kim Y; Geiger JH; Hahn S; Sigler PB Crystal structure of a yeast TBP/TATA-box complex. Nature 1993, 365, 512-520. [PubMed: 8413604]

9. Rice PA; Yang S; Mizuuchi K; Nash HA Crystal structure of an IHF-DNA complex: a proteininduced DNA U-turn. Cell 1996, 87, 1295-1306. [PubMed: 8980235]

10. Swinger KK; Lemberg KM; Zhang Y; Rice PA Flexible DNA bending in HU-DNA cocrystal structures. EMBO J. 2003, 22, 3749-3760. [PubMed: 12853489]

11. Mouw KM; Rice PA Shaping the Borrelia burgdorferi genome: crystal structure and binding properties of the DNA-bending Hbb. Molecular Microbiology 2007, 63, 1319-1330. [PubMed: 17244195]

12. Czapla L; Peters JP; Rueter EM; Olson WK; Maher LJ 3rd, Understanding apparent DNA flexibility enhancement by HU and HMGB architectural proteins. J Mol Biol 2011, 409, 278-289. [PubMed: 21459097]

13. Olson WK; Gorin AA; Lu XJ; Hock LM; Zhurkin VB DNA sequence-dependent deformability deduced from protein-DNA crystal complexes. Proc. Natl. Acad. Sci. U S A 1998, 95, $11163-$ 11168. [PubMed: 9736707]

14. Olson WK; Zhurkin VB Modeling DNA deformations. Curr. Opin. Struct. Biol 2000, 10, 286-297. [PubMed: 10851199]

15. Morozov AV; Havranek JJ; Baker D; Siggia ED Protein-DNA binding specificity predictions with structural models. Nucleic Acids Res 2005, 33, 5781-5798. [PubMed: 16246914]

16. Morozov AV; Fortney K; Gaykalova DA; Studitsky VM; Widom J; Siggia ED Using DNA mechanics to predict in vitro nucleosome positions and formation energies. Nucleic Acids Res 2009, 37, 4707-4722. [PubMed: 19509309]

17. Dixit SB; Beveridge DL; Case DA; Cheatham TE 3rd; Giudice E; Lankas F; Lavery R; Maddocks JH; Osman R; Sklenar H; Thayer KM; Varnai P. Molecular dynamics simulations of the 136 unique tetranucleotide sequences of DNA oligonucleotides. II: sequence context effects on the dynamical structures of the 10 unique dinucleotide steps. Biophys J 2005, 89, 3721-3740. [PubMed: 16169978]

18. Lavery R; Zakrzewska K; Beveridge D; Bishop TC; Case DA; Cheatham T 3rd; Dixit S; Jayaram B; Lankas F; Laughton C; Maddocks JH; Michon A; Osman R; Orozco M; Perez A; Singh T; Spackova N; Sponer J. A systematic molecular dynamics study of nearest-neighbor effects on base pair and base pair step conformations and fluctuations in B-DNA. Nucleic Acids Res 2010, 38, 299-313. [PubMed: 19850719]

19. Pasi M; Maddocks JH; Beveridge D; Bishop TC; Case DA; Cheatham T 3rd; Dans PD; Jayaram B; Lankas F; Laughton C; Mitchell J; Osman R; Orozco M; Perez A; Petkeviciute D; Spackova 
N; Sponer J; Zakrzewska K; Lavery R. muABC: a systematic microsecond molecular dynamics study of tetranucleotide sequence effects in B-DNA. Nucleic Acids Res 2014, 42, 12272-12283. [PubMed: 25260586]

20. Olson WK; Zhurkin VB Working the kinks out of nucleosomal DNA. Curr Opin Struct Biol 2011, 21, 348-357. [PubMed: 21482100]

21. Lequieu J; Schwartz DC; de Pablo JJ In silico evidence for sequence-dependent nucleosome sliding. Proc Natl Acad Sci U S A 2017, 114, E9197-E9205. [PubMed: 29078285]

22. Chakraborty D; Hori N; Thirumalai D. Sequence-dependent three interaction site model for singleand double-stranded DNA. J. Chem. Theory. Comp 2018, 14, 3763-3779.

23. Swinger KK; Rice PA IHF and HU: flexible architects of bent DNA. Curr. Opin. Struct. Biol 2004, 14, 28-35. [PubMed: 15102446]

24. Wojtuszewski K; Hawkins ME; Cole JL; Mukerji I. HU binding to DNA: evidence for multiple complex formation and DNA bending. Biochemistry 2001, 40, 2588-2598. [PubMed: 11327882]

25. van Noort J; Verbrugge S; Goosen N; Dekker C; Dame RT Dual architectural roles of HU: formation of flexible hinges and rigid filaments. Proc. Natl. Acad. Sci. USA 2004, 101, 69696974. [PubMed: 15118104]

26. Erie DA; Yang G; Schultz HC; Bustamante C. DNA bending by Cro protein in specific and nonspecific complexes: implications for protein site recognition and specificity. Science 1994, 266, 1562-1566. [PubMed: 7985026]

27. Seong GH; Kobatake E; Miura K; Nakazawa A; Aizawa M. Direct atomic force microscopy visualization of integration host factor-induced DNA bending structure of the promoter regulatory region on the Pseudomonas TOL plasmid. Biochem Biophys Res Commun 2002, 291, 361-366. [PubMed: 11846413]

28. Kong M; Liu L; Chen X; Driscoll KI; Mao P; Bohm S; Kad NM; Watkins SC; Bernstein KA; Wyrick JJ; Min JH; Van Houten B. Single-molecule imaging reveals that Rad4 employs a dynamic DNA damage recognition process. Mol Cell 2016, 64, 376-387. [PubMed: 27720644]

29. Wang H; Yang Y; Schofield MJ; Du C; Fridman Y; Lee SD; Larson ED; Drummond JT; Alani E; Hsieh P; Erie DA DNA bending and unbending by MutS govern mismatch recognition and specificity. Proc. Natl. Acad. Sci. U S A 2003, 100, 14822-14827. [PubMed: 14634210]

30. Buechner CN; Maiti A; Drohat AC; Tessmer I. Lesion search and recognition by thymine DNA glycosylase revealed by single molecule imaging. Nucleic Acids Res 2015, 43, 2716-2729. [PubMed: 25712093]

31. Klostermeier D; Millar DP Time-resolved fluorescence resonance energy transfer: a versatile tool for the analysis of nucleic acids. Biopolymers 2001, 61, 159-179. [PubMed: 11987179]

32. Lyubchenko YL; Shlyakhtenko LS Imaging of DNA and Protein-DNA Complexes with Atomic Force Microscopy. Crit Rev Eukaryot Gene Expr 2016, 26, 63-96. [PubMed: 27278886]

33. Beckwitt EC; Kong M; Van Houten B. Studying protein-DNA interactions using atomic force microscopy. Semin Cell Dev Biol 2018, 73, 220-230. [PubMed: 28673677]

34. Roy R; Hohng S; Ha T. A practical guide to single-molecule FRET. Nat Methods 2008, 5, 507516. [PubMed: 18511918]

35. Sass LE; Lanyi C; Weninger K; Erie DA Single-molecule FRET TACKLE reveals highly dynamic mismatched DNA-MutS complexes. Biochemistry 2010, 49, 3174-3190. [PubMed: 20180598]

36. Vafabakhsh R; Ha T. Extreme bendability of DNA less than 100 base pairs long revealed by single-molecule cyclization. Science 2012, 337, 1097-1101. [PubMed: 22936778]

37. Singh D; Wang Y; Mallon J; Yang O; Fei J; Poddar A; Ceylan D; Bailey S; Ha T. Mechanisms of improved specificity of engineered Cas9s revealed by single-molecule FRET analysis. Nat Struct Mol Biol 2018, 25, 347-354. [PubMed: 29622787]

38. Schuler B; Lipman EA; Eaton WA Probing the free-energy surface for protein folding with single-molecule fluorescence spectroscopy. Nature 2002, 419, 743-747. [PubMed: 12384704]

39. Lipman EA; Schuler B; Bakajin O; Eaton WA Single-molecule measurement of protein folding kinetics. Science 2003, 301, 1233-1235. [PubMed: 12947198]

40. Merchant KA; Best RB; Louis JM; Gopich IV; Eaton WA Characterizing the unfolded states of proteins using single-molecule FRET spectroscopy and molecular simulations. Proc Natl Acad Sci U S A 2007, 104, 1528-1533. [PubMed: 17251351] 
41. Schuler B; Eaton WA Protein folding studied by single-molecule FRET. Curr Opin Struct Biol 2008, 18, 16-26. [PubMed: 18221865]

42. Gopich IV; Szabo A. Single-molecule FRET with diffusion and conformational dynamics. J Phys Chem B 2007, 111, 12925-12932. [PubMed: 17929964]

43. Chakraborty S; Steinbach PJ; Paul D; Mu H; Broyde S; Min JH; Ansari A. Enhanced spontaneous DNA twisting/bending fluctuations unveiled by fluorescence lifetime distributions promote mismatch recognition by the Rad4 nucleotide excision repair complex. Nucleic Acids Res 2018, 46, 1240-1255. [PubMed: 29267981]

44. Nash HA Regulation of Gene Expression in E. coli Chapman and Hall: New York, 1996.

45. Craig NL; Nash HAE coli integration host factor binds to specific sites in DNA. Cell 1984, 39 , 707-716. [PubMed: 6096022]

46. Yang CC; Nash HA The interaction of E. coli IHF protein with its specific binding sites. Cell 1989, 57, 869-880. [PubMed: 2541927]

47. Goodrich JA; Schwartz ML; McClure WR Searching for and predicting the activity of sites for DNA binding proteins: compilation and analysis of the binding sites for Escherichia coli integration host factor (IHF). Nucleic Acids Res. 1990, 18, 4993-5000. [PubMed: 2205834]

48. Engelhorn M; Boccard F; Murtin C; Prentki P; Geiselmann J. In vivo interaction of the Escherichia coli integration host factor with its specific binding sites. Nucleic Acids Res 1995, 23, 2959-2965.

49. Hales LM; Gumport RI; Gardner JF Determining the DNA sequence elements required for binding integration host factor to two different target sites. J. Bacteriol 1994, 176, 2999-3006. [PubMed: 8188600]

50. Hales LM; Gumport RI; Gardner JF Examining the contribution of a dA+dT element to the conformation of Escherichia coli integration host factor-DNA complexes. Nucleic Acids Res. 1996, 24, 1780-1786. [PubMed: 8650000]

51. Holbrook JA; Tsodikov OV; Saecker RM; Record MT Jr. Specific and non-specific interactions of integration host factor with DNA: thermodynamic evidence for disruption of multiple IHF surface salt-bridges coupled to DNA binding. Journal of molecular biology. 2001, 310, 379-401. [PubMed: 11428896]

52. Vander Meulen KA; Saecker RM; Record MT Jr. Formation of a wrapped DNA-protein interface: experimental characterization and analysis of the large contributions of ions and water to the thermodynamics of binding IHF to H' DNA. Journal of molecular biology. 2008, 377, 9-27. [PubMed: 18237740]

53. Rice PA; Correll CC Introduction. In Protein-Nucleic Acid Interactions, Rice PA; Correll CC, Eds. Royal Society of Chemistry: Cambridge, 2008.

54. Lawson CL; Berman HM Indirect readout of DNA sequence by proteins. In Protein-Nucleic Acid Interactions, Rice PA; Correll CC, Eds. Royal Society of Chemistry: Cambridge, 2008.

55. Swinger KK; Rice PA Structure-based Analysis of HU-DNA Binding. Journal of molecular biology. 2007, 365, 1005-1016. [PubMed: 17097674]

56. Grove A; Galeone A; Mayol L; Geiduschek EP Localized DNA flexibility contributes to target site selection by DNA-bending proteins. Journal of molecular biology. 1996, 260, 120-125. [PubMed: 8764394]

57. Lynch TW; Read EK; Mattis AN; Gardner JF; Rice PA Integration host factor: putting a twist on protein-DNA recognition. Journal of molecular biology. 2003, 330, 493-502. [PubMed: 12842466]

58. Laxmikanthan G; Xu C; Brilot AF; Warren D; Steele L; Seah N; Tong W; Grigorieff N; Landy A; Van Duyne GD Structure of a Holliday junction complex reveals mechanisms governing a highly regulated DNA transaction. Elife 2016, 5.

59. Vivas P; Velmurugu Y; Kuznetsov SV; Rice PA; Ansari A. Mapping the Transition State for DNA Bending by IHF. J Mol Biol 2012, 418, 300-315. [PubMed: 22370561]

60. Sugimura S Kinetic and steady-state studies of binding and bending of lambda phage DNA by Integration Host Factor. Ph.D. thesis, Yale University, New Haven, CT, 2005.

61. Sugimura S; Crothers DM Stepwise binding and bending of DNA by Escherichia coli integration host factor. Proc. Natl. Acad. Sci. USA 2006, 103, 18510-18514. [PubMed: 17116862] 
62. Vivas P; Kuznetsov SV; Ansari A. New insights into the transition pathway from nonspecific to specific complex of DNA with Escherichia coli integration host factor. J Phys Chem B 2008, 112, 5997-6007. [PubMed: 18461910]

63. O'Connor DV Time-correlated single photon counting. Academic Press: London, 1984.

64. Steinbach PJ; Ionescu R; Matthews CR Analysis of kinetics using a hybrid maximum-entropy/ nonlinear-least-squares method: application to protein folding. Biophys. J 2002, 82, 2244-2255. [PubMed: 11916879]

65. Steinbach PJ Filtering artifacts from lifetime distributions when maximizing entropy using a bootstrapped model. Anal Biochem 2012, 427, 102-105. [PubMed: 22504734]

66. Brent RP Algorithms for Minimization without Derivatives. Prentice-Hall: Englewood Cliffs, NJ. Reprinted by Dover, Mineola, New York, 2002 and 2013.

67. Esposito R; Mensitieri G; de Nicola S. Improved maximum entropy method for the analysis of fluorescence spectroscopy data: evaluating zero-time shift and assessing its effect on the determination of fluorescence lifetimes. Analyst 2015, 140, 8138-8147. [PubMed: 26541293]

68. Lorenz M; Hillisch A; Goodman SD; Diekmann S. Global structure similarities of intact and nicked DNA complexed with IHF measured in solution by fluorescence resonance energy transfer. Nucleic Acids Res. 1999, 27, 4619-4625. [PubMed: 10556318]

69. Kuznetsov SV; Sugimura S; Vivas P; Crothers DM; Ansari A. Direct observation of DNA bending/ unbending kinetics in complex with DNA-bending protein IHF. Proc. Natl. Acad. Sci. USA 2006, 103, 18515-18520. [PubMed: 17124171]

70. Velmurugu Y; Vivas P; Connolly M; Kuznetsov SV; Rice PA; Ansari A. Two-step interrogation then recognition of DNA binding site by Integration Host Factor: an architectural DNA-bending protein. Nucleic Acids Res 2018, 46, 1741-1755. [PubMed: 29267885]

71. Tsodikov OV; Holbrook JA; Shkel IA; Record MT Jr. Analytic binding isotherms describing competitive interactions of a protein ligand with specific and nonspecific sites on the same DNA oligomer. Biophys J 2001, 81, 1960-1969. [PubMed: 11566770]

72. Aeling KA; Opel ML; Steffen NR; Tretyachenko-Ladokhina V; Hatfield GW; Lathrop RH; Senear DF Indirect recognition in sequence-specific DNA binding by Escherichia coli integration host factor: the role of DNA deformation energy. J. Biol. Chem 2006, 281, 39236-39248. [PubMed: 17035240]

73. Lohman TM; Mascotti DP Thermodynamics of ligand-nucleic acid interactions. Methods Enzymol. 1992, 212, 400-424. [PubMed: 1518457]

74. Record MT Jr.; Anderson CF; Lohman TM Thermodynamic analysis of ion effects on the binding and conformational equilibria of proteins and nucleic acids: the roles of ion association or release, screening, and ion effects on water activity. Q. Rev. Biophys 1978, 11, 103-178. [PubMed: 353875]

75. Manning GS The molecular theory of polyelectrolyte solutions with applications to the electrostatic properties of polynucleotides. Q. Rev. Biophys 1978, 11, 179-246. [PubMed: 353876]

76. Jen-Jacobson L; Jacobson LA Role of water and effects of small ions in site-specific protein-DNA interactions. In Protein-Nucleic Acid Interactions, Rice PA; Cornell CC, Eds. Royal Society of Chemistry: Cambridge, 2008; pp 13-46.

77. Vivas P; Velmurugu Y; Kuznetsov SV; Rice PA; Ansari A. Global analysis of ion dependence unveils hidden steps in DNA binding and bending by integration host factor. J Chem Phys 2013, 139, 121927. [PubMed: 24089739]

78. Engler LE; Sapienza P; Dorner LF; Kucera R; Schildkraut I; Jen-Jacobson L. The energetics of the interaction of BamHI endonuclease with its recognition site GGATCC. J Mol Biol 2001, 307, 619-636. [PubMed: 11254386]

79. Engler LE; Welch KK; Jen-Jacobson L. Specific binding by EcoRV endonuclease to its DNA recognition site GATATC. J Mol Biol 1997, 269, 82-101. [PubMed: 9193002]

80. Lesser DR; Kurpiewski MR; Jen-Jacobson L. The energetic basis of specificity in the Eco RI endonuclease--DNA interaction. Science 1990, 250, 776-786. [PubMed: 2237428]

81. Record MT Jr.; Anderson CF; Mills P; Mossing M; Roe JH Ions as regulators of protein-nucleic acid interactions in vitro and in vivo. Adv Biophys 1985, 20, 109-135. [PubMed: 3914831] 
82. Lorenz M; Hillisch A; Payet D; Buttinelli M; Travers A; Diekmann S. DNA bending induced by high mobility group proteins studied by fluorescence resonance energy transfer. Biochemistry 1999, 38, 12150-12158. [PubMed: 10508419]

83. Friedman DI Integration host factor: a protein for all reasons. Cell 1988, 55, 545-554. [PubMed: 2972385]

84. Landy A. Dynamic, structural, and regulatory aspects of lambda site-specific recombination. Annu Rev Biochem 1989, 58, 913-949. [PubMed: 2528323]

85. Travers A. DNA-protein interactions: IHF--the master bender. Curr. Biol 1997, 7, R252-254. [PubMed: 9162504]

86. Goodman SD; Velten NJ; Gao Q; Robinson S; Segall AM In vitro selection of integration host factor binding sites. J Bacteriol 1999, 181, 3246-3255. [PubMed: 10322029]

87. Steffen NR; Murphy SD; Tolleri L; Hatfield GW; Lathrop RH DNA sequence and structure: direct and indirect recognition in protein-DNA binding. Bioinformatics 2002, 18 Suppl 1, S22-30. [PubMed: 12169527]

88. Aeling KA; Steffen NR; Johnson M; Hatfield GW; Lathrop RH; Senear DF DNA deformation energy as an indirect recognition mechanism in protein-DNA interactions. IEEE/ACM Trans Comput Biol Bioinform 2007, 4, 117-125. [PubMed: 17277419]

89. Khrapunov S; Brenowitz M; Rice PA; Catalano CE Binding then bending: A mechanism for wrapping DNA. Proc. Natl. Acad. Sci. USA 2006, 103, 19217-19218. [PubMed: 17159146]

90. Mengeritsky G; Goldenberg D; Mendelson I; Giladi H; Oppenheim AB Genetic and biochemical analysis of the integration host factor of Escherichia coli. J Mol Biol 1993, 231, 646-657. [PubMed: 8515442]

91. Wang S; Cosstick R; Gardner JF; Gumport RI The specific binding of Escherichia coli integration host factor involves both major and minor grooves of DNA. Biochemistry 1995, 34, 13082-13090. [PubMed: 7548068]

92. Yang SW; Nash HA Comparison of protein binding to DNA in vivo and in vitro: defining an effective intracellular target. Embo. J 1995, 14, 6292-6300. [PubMed: 8557048]

93. Ali BM; Amit R; Braslavsky I; Oppenheim AB; Gileadi O; Stavans J. Compaction of single DNA molecules induced by binding of integration host factor (IHF). Proc. Natl. Acad. Sci. U S A 2001, 98, 10658-10663. [PubMed: 11535804]

94. Lee EC; MacWilliams MP; Gumport RI; Gardner JF Genetic analysis of Escherichia coli integration host factor interactions with its bacteriophage lambda H' recognition site. J Bacteriol 1991, 173, 609-617. [PubMed: 1824766]

95. Pinson V; Takahashi M; Rouviere-Yaniv J. Differential binding of the Escherichia coli HU, homodimeric forms and heterodimeric form to linear, gapped and cruciform DNA. Journal of molecular biology. 1999, 287, 485-497. [PubMed: 10092454]

96. Castaing B; Zelwer C; Laval J; Boiteux S. HU protein of Escherichia coli binds specifically to DNA that contains single-strand breaks or gaps. J. Biol. Chem 1995, 270, 10291-10296. [PubMed: 7730334]

97. Xiao B; Johnson RC; Marko JF Modulation of HU-DNA interactions by salt concentration and applied force. Nucleic Acids Res 2010, 38, 6176-6185. [PubMed: 20497998]

98. Lin J; Chen H; Droge P; Yan J. Physical organization of DNA by multiple non-specific DNAbinding modes of integration host factor (IHF). PLoS One 2012, 7, e49885. [PubMed: 23166787]

99. Sagi D; Friedman N; Vorgias C; Oppenheim AB; Stavans J. Modulation of DNA conformations through the formation of alternative high-order HU-DNA complexes. Journal of molecular biology. 2004, 341, 419-428. [PubMed: 15276833]

100. Coats JE; Lin Y; Rueter E; Maher LJ 3rd; Rasnik I. Single-molecule FRET analysis of DNA binding and bending by yeast HMGB protein Nhp6A. Nucleic Acids Res 2013, 41, 1372-1381. [PubMed: 23221634]

101. Murugesapillai D; McCauley MJ; Maher LJ 3rd; Williams MC Single-molecule studies of highmobility group B architectural DNA bending proteins. Biophys Rev 2017, 9, 17-40. [PubMed: 28303166] 
102. Graham JS; Johnson RC; Marko JF Concentration-dependent exchange accelerates turnover of proteins bound to double-stranded DNA. Nucleic Acids Res 2011, 39, 2249-2259. [PubMed: 21097894]

103. Joshi CP; Panda D; Martell DJ; Andoy NM; Chen TY; Gaballa A; Helmann JD; Chen P. Direct substitution and assisted dissociation pathways for turning off transcription by a MerR-family metalloregulator. Proc Natl Acad Sci U S A 2012, 109, 15121-15126. [PubMed: 22949686]

104. Loparo JJ; Kulczyk AW; Richardson CC; van Oijen AM Simultaneous single-molecule measurements of phage $\mathrm{T} 7$ replisome composition and function reveal the mechanism of polymerase exchange. Proc Natl Acad Sci U S A 2011, 108, 3584-3589. [PubMed: 21245349]

105. Giuntoli RD; Linzer NB; Banigan EJ; Sing CE; de la Cruz MO; Graham JS; Johnson RC; Marko JF DNA-Segment-Facilitated Dissociation of Fis and NHP6A from DNA Detected via Single-Molecule Mechanical Response. J Mol Biol 2015, 427, 3123-3136. [PubMed: 26220077]

106. Hadizadeh N; Johnson RC; Marko JF Facilitated Dissociation of a Nucleoid Protein from the Bacterial Chromosome. J Bacteriol 2016, 198, 1735-1742. [PubMed: 27044624]

107. Sing CE; Olvera de la Cruz M; Marko JF Multiple-binding-site mechanism explains concentration-dependent unbinding rates of DNA-binding proteins. Nucleic Acids Res 2014, 42, 3783-3791. [PubMed: 24393773]

108. Cocco S; Marko JF; Monasson R. Stochastic ratchet mechanisms for replacement of proteins bound to DNA. Phys Rev Lett 2014, 112, 238101. [PubMed: 24972228] 

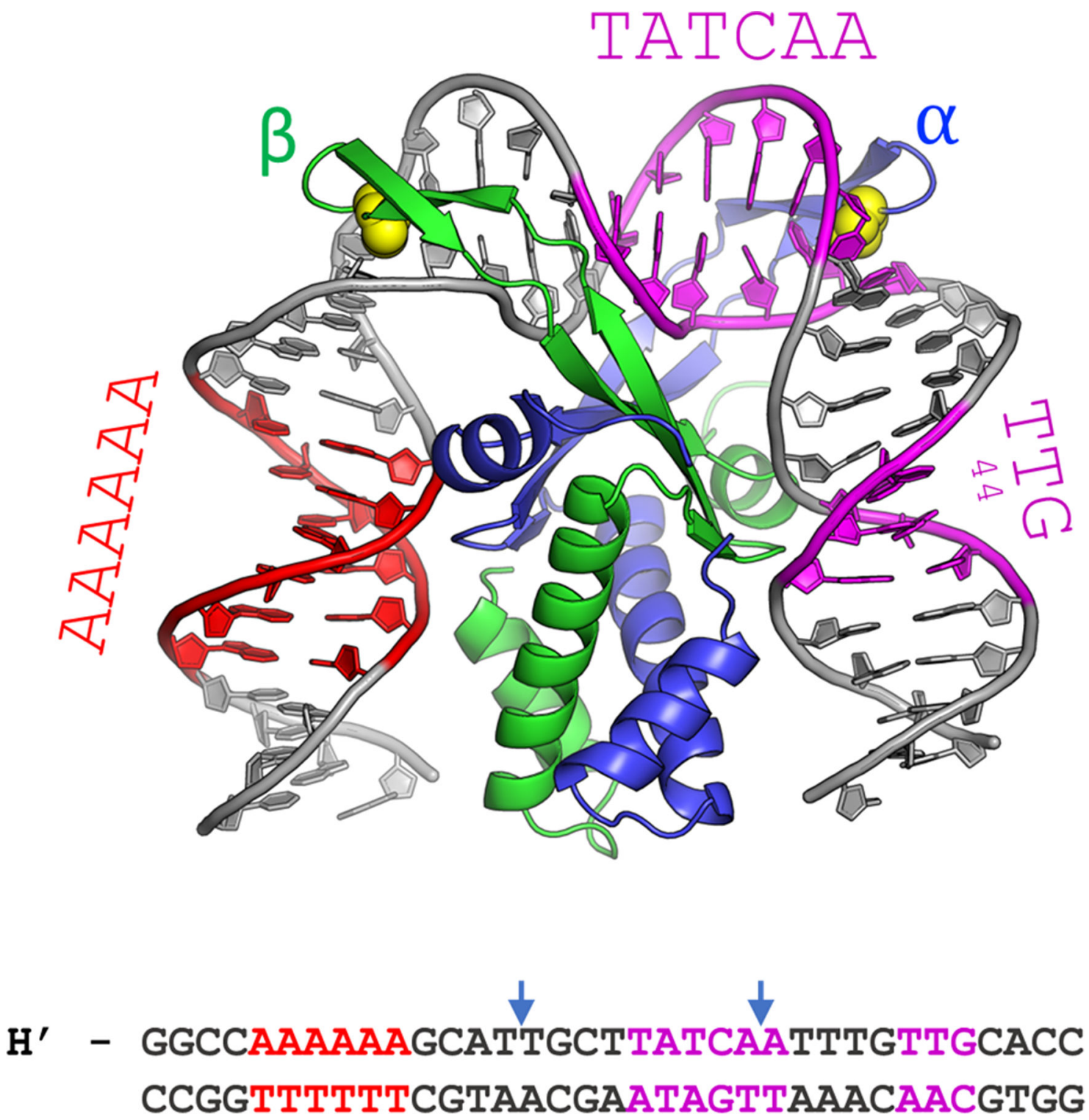

Figure 1.

The cocrystal structure of IHF in complex with the $\mathrm{H}^{\prime}$ binding site from phage lambda.

The $\alpha$ - and $\beta$-chains of the IHF protein are shown in blue and green, respectively, with the conserved proline residues shown as yellow spheres. The DNA is shown in gray, with the consensus region highlighted in magenta and the A-tract in red. The sequence shown below is that of the 35-mer that contains the $\mathrm{H}^{\prime}$ binding site, which was used to obtain the cocrystal structure with IHF. In the complex, the DNA is sharply kinked at the two sites indicated by the blue arrows. In the DNA oligomer used for the structural studies, the DNA was nicked at a position shifted $1 \mathrm{bp}$ to the 3 '-side of the left blue arrow, to facilitate crystal packing. That nick was "sealed" in silico to generate the model shown (starting from PDB ID 1IHF). 

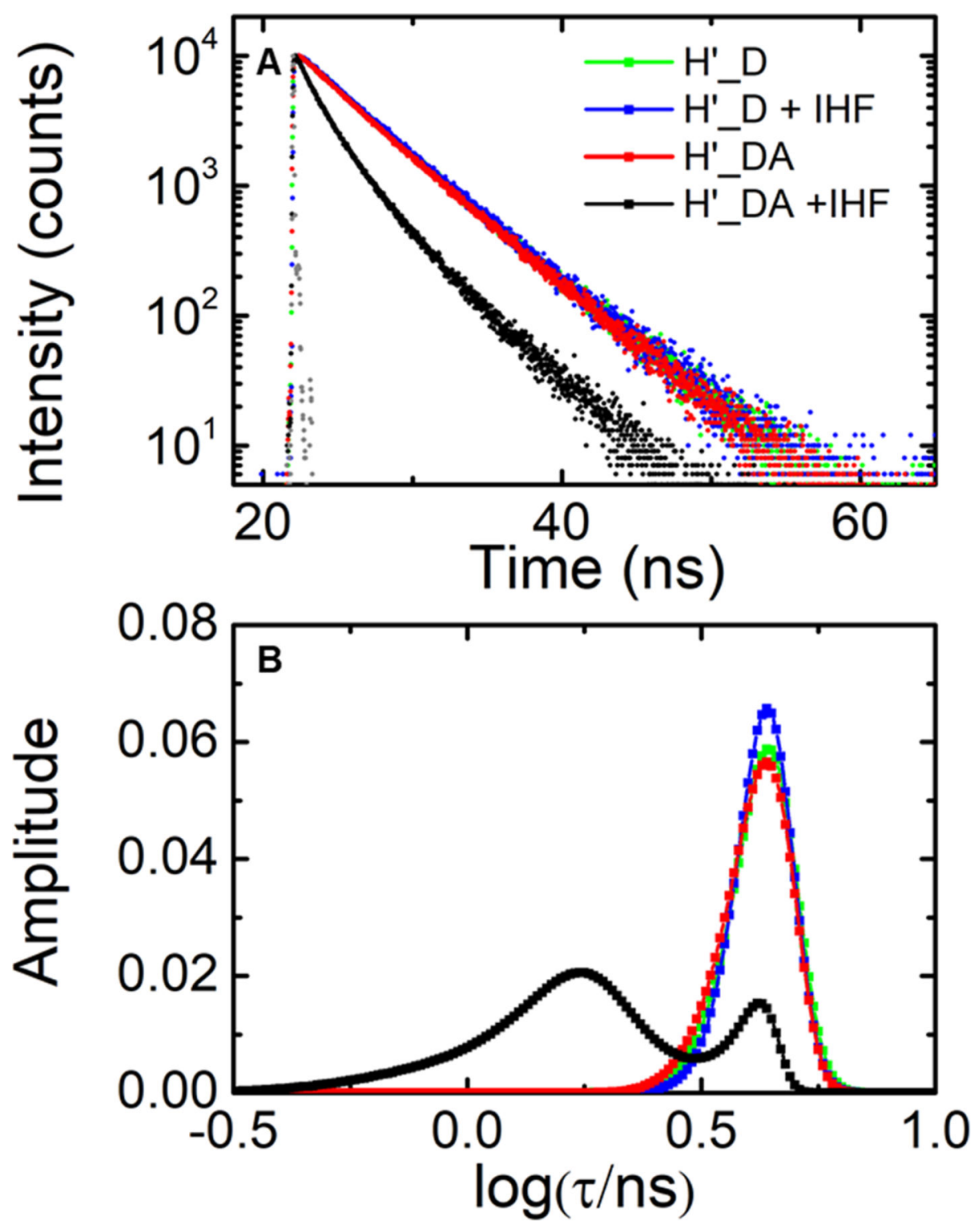

Figure 2.

Fluorescence lifetime measurements on IHF-H' complex in design I constructs. (A) Fluorescence intensity decay traces measured on $\mathrm{H}^{\prime}$ labeled with fluorescein and TAMRA (H'_DA) are shown in the absence (red) and presence (black) of IHF. The corresponding donor-only (H'_D) decay traces are also shown in the absence (green) and presence (blue) of IHF. Measurements were done with $5 \mu \mathrm{M}$ DNA and $5 \mu \mathrm{M}$ IHF. The instrument response function (gray) is shown for comparison. (B) The MEM lifetime distributions obtained from the fluorescence decay traces are shown. The amplitudes of the distributions are normalized to add up to one. 

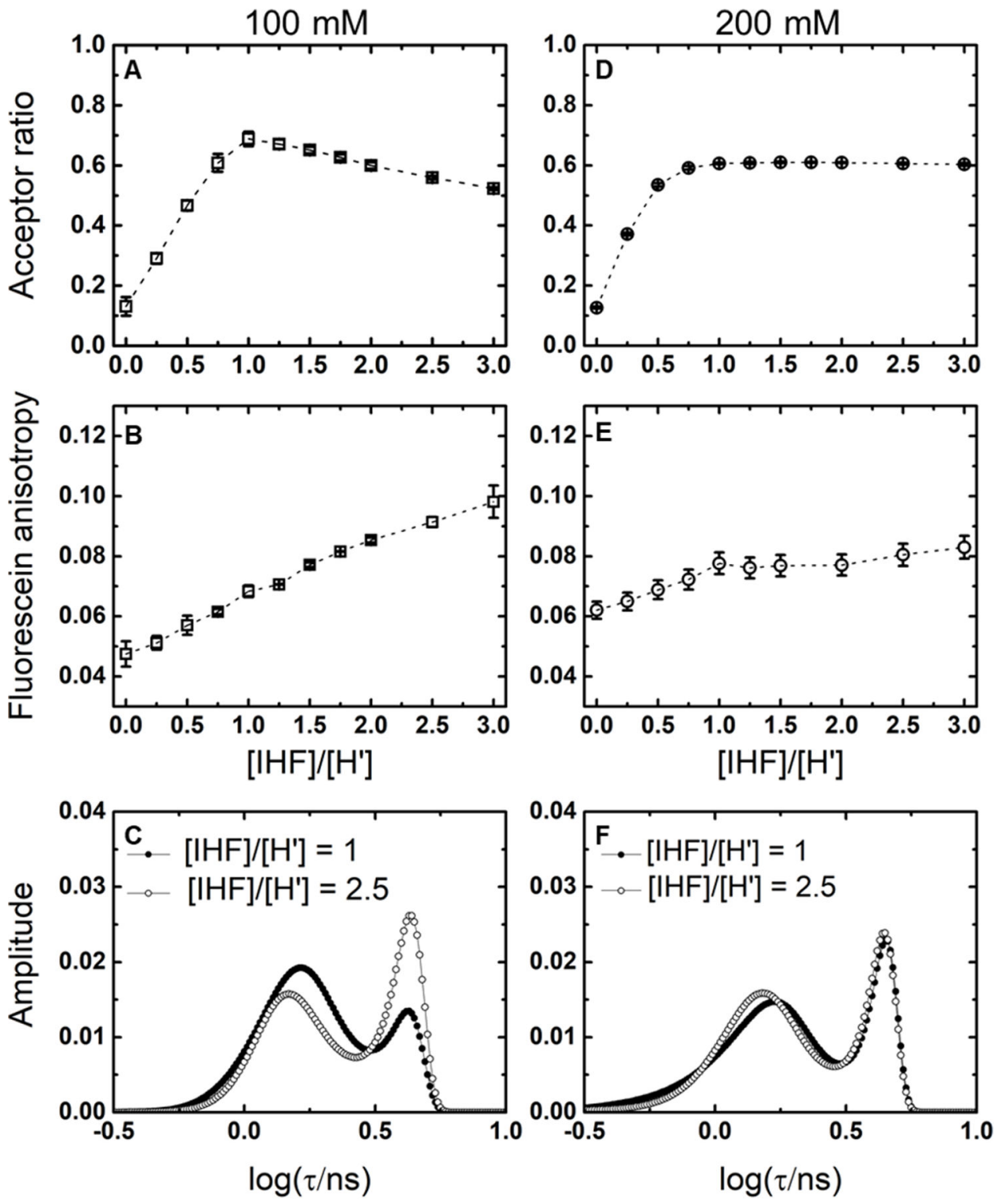

Figure 3.

Binding isotherms and MEM distributions for the IHF-H' complex at 100 and $200 \mathrm{mM} \mathrm{KCl}$. $(\mathbf{A}, \mathbf{D})$ Acceptor ratio measurements and $(\mathbf{B}, \mathbf{E})$ anisotropy measurements are shown for $1 \mathrm{uM}$ H'_DA and varying concentration of IHF in $100 \mathrm{mM} \mathrm{KCl} \mathrm{(A,B)} \mathrm{and} 200 \mathrm{mM} \mathrm{KCl}(\mathbf{D}, \mathbf{E})$.

(C,F) The MEM lifetime distributions obtained from fluorescence decay traces measured for IHF-H' are shown for $[\mathrm{IHF}] /[\mathrm{DNA}]=1$ (continuous lines) and $[\mathrm{IHF}] /[\mathrm{DNA}]=2.5$ (dashed lines) in $100 \mathrm{mM} \mathrm{KCl}(\mathbf{C})$ and $200 \mathrm{mM} \mathrm{KCl}(\mathbf{F})$. DNA concentrations for the lifetime measurements were $5 \mu \mathrm{M}$. 

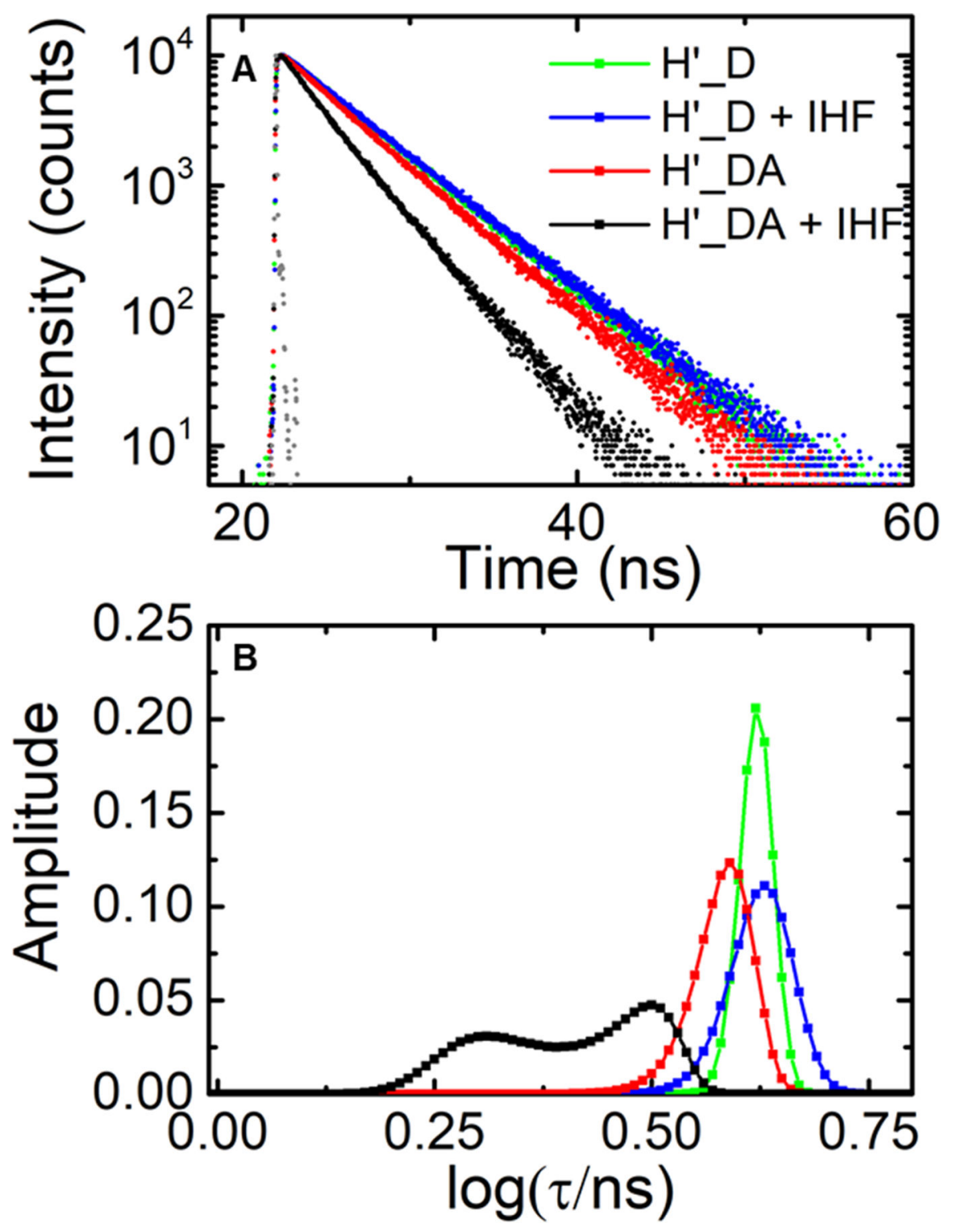

Figure 4.

Fluorescence lifetime measurements on IHF-H' complex in design II constructs. (A) Fluorescence intensity decay traces measured on H' labeled with fluorescein and Atto550 (H'_DA) are shown in the absence (red) and presence (black) of IHF. The corresponding donor-only (H'_D) decay traces are also shown in the absence (green) and presence (blue) of IHF. Measurements were done with $5 \mu \mathrm{M}$ DNA and $5 \mu \mathrm{M}$ IHF. The instrument response function (gray) is shown for comparison. (B) The MEM lifetime distributions obtained from the fluorescence decay traces are shown. The amplitudes of the distributions are normalized to add up to one. 

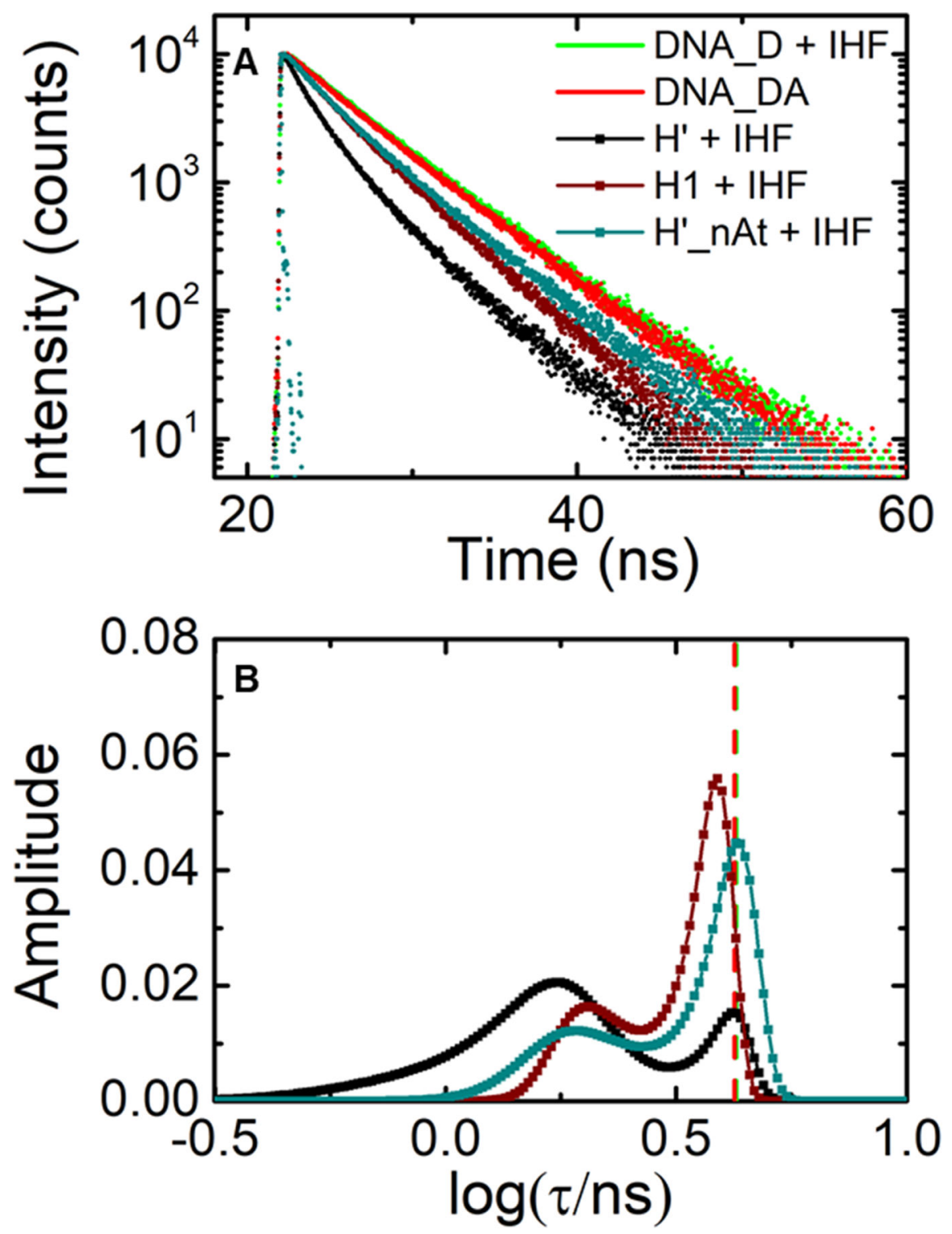

Figure 5.

Fluorescence lifetime measurements on IHF-H' compared with IHF-H1 (design I constructs). (A) Fluorescence intensity decay traces are shown for H'_DA (black), H1_DA (maroon), and H'_nAt_DA (blue-green), measured in the presence of IHF. Decay traces on DNA_DA in the absence of IHF (red) and DNA_D in presence of IHF (green) are shown for comparison. Measurements were done with $5 \mu \mathrm{M}$ DNA and $5 \mu \mathrm{M}$ IHF. The instrument response function (gray) is shown for comparison. (B) The MEM lifetime distributions obtained from the fluorescence decay traces measured for IHF-H' (black), IHFH1 (maroon), and IHF-H'_nAt (blue-green) are shown. The amplitudes of the distributions are normalized to add up to one. The average lifetime for the DNA_DA in the absence of IHF (red) and DNA_D in presence of IHF (green) are indicated by the vertical dashed lines. 

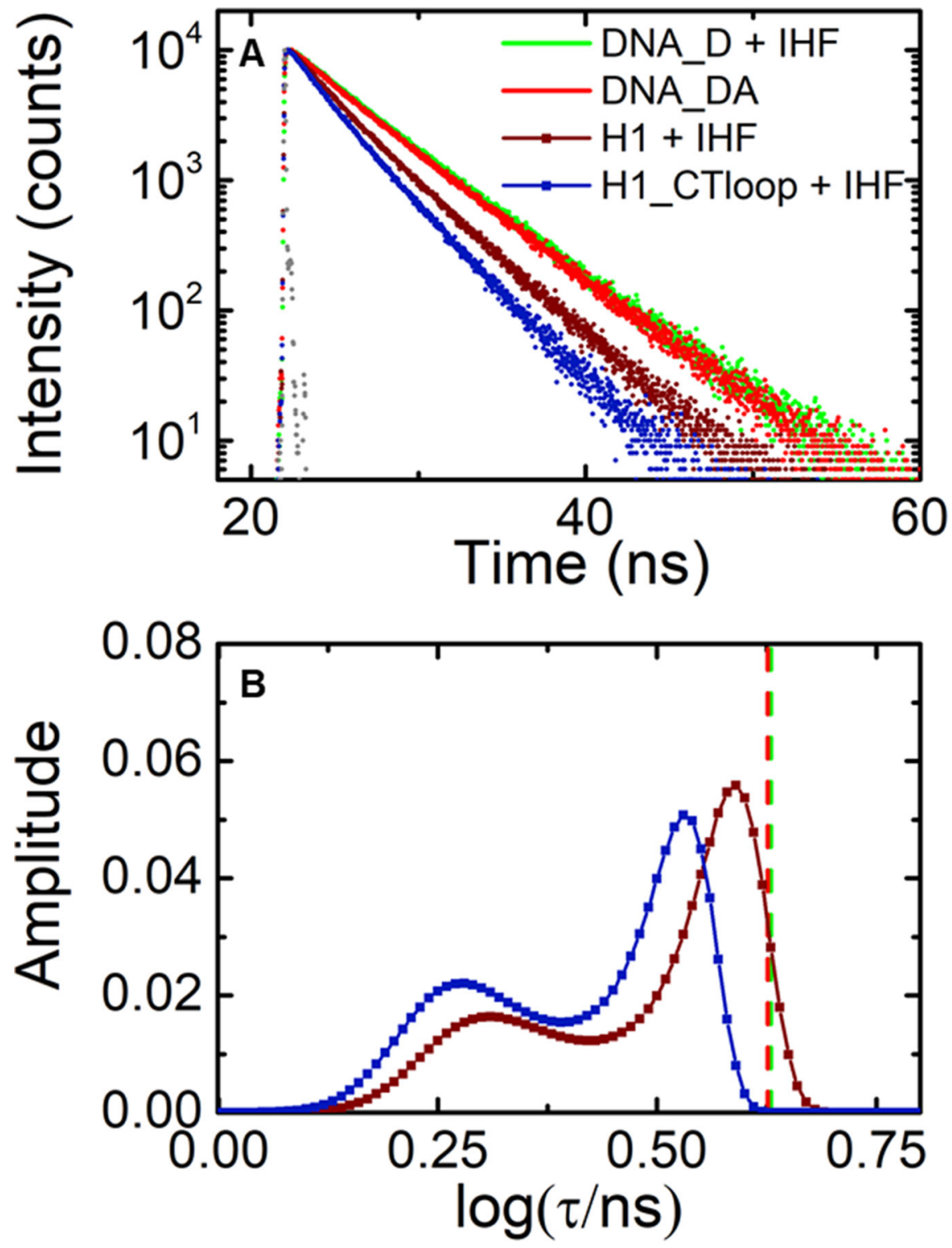

Figure 6.

Fluorescence lifetime measurements on IHF-H1 compared for matched and mismatched (design I constructs). (A) Fluorescence intensity decay traces measured on H1_DA (maroon) and H1-CTloop_DA (blue), both in the presence of IHF. Decay traces on DNA_DA in the absence of IHF (red) and DNA_D in presence of IHF (green) are shown for comparison. Measurements were done with $5 \mu \mathrm{M}$ DNA and $5 \mu \mathrm{M}$ IHF. The instrument response function (gray) is shown for comparison. (B) The MEM lifetime distributions obtained from the fluorescence decay traces measured for H1_DA (maroon) and H1_CTloop_DA (blue) are shown. The amplitudes of the distributions are normalized to add up to one. The average lifetime for the DNA_DA in the absence of IHF (red) and DNA_D in presence of IHF (green) are indicated by the vertical dashed lines. 

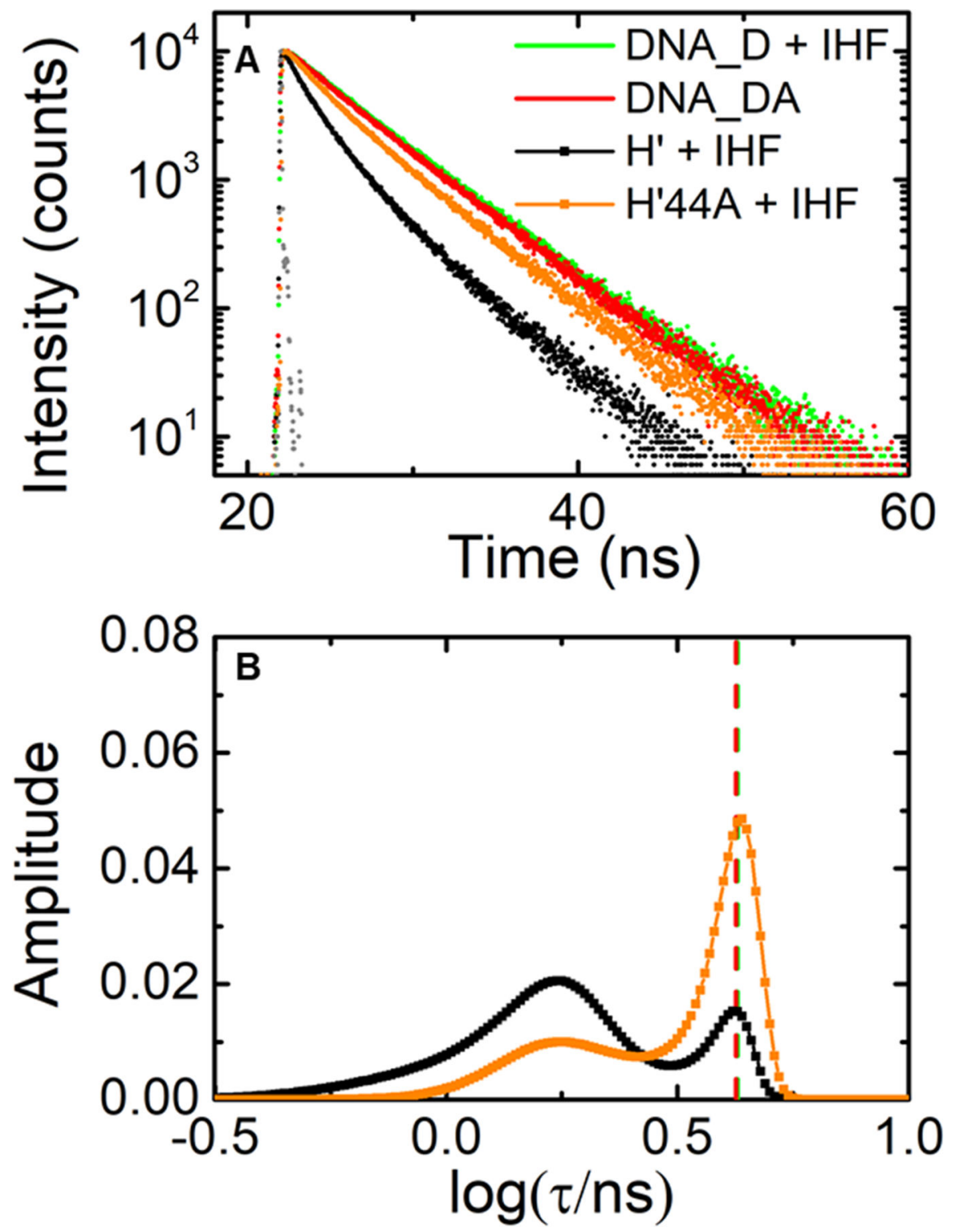

Figure 7.

Fluorescence lifetime measurements on IHF-H' compared with IHF-H'44A (design I constructs). (A) Fluorescence intensity decay traces measured on H'_DA (black) and H'44A_DA (orange), both in the presence of IHF. Decay traces on DNA_DA in the absence of IHF (red) and DNA_D in presence of IHF (green) are shown for comparison. Measurements were done with $5 \mu \mathrm{M}$ DNA and $5 \mu \mathrm{M}$ IHF. The instrument response function (gray) is shown for comparison. (B) The MEM lifetime distributions obtained from fluorescence decay traces measured for H'_DA (black) and H'44A_DA (orange) in the presence of IHF are shown. The amplitudes of the distributions are normalized to add up to one. The average lifetime for the DNA_DA in the absence of IHF (red) and DNA_D in presence of IHF (green) are indicated by the vertical dashed lines. 


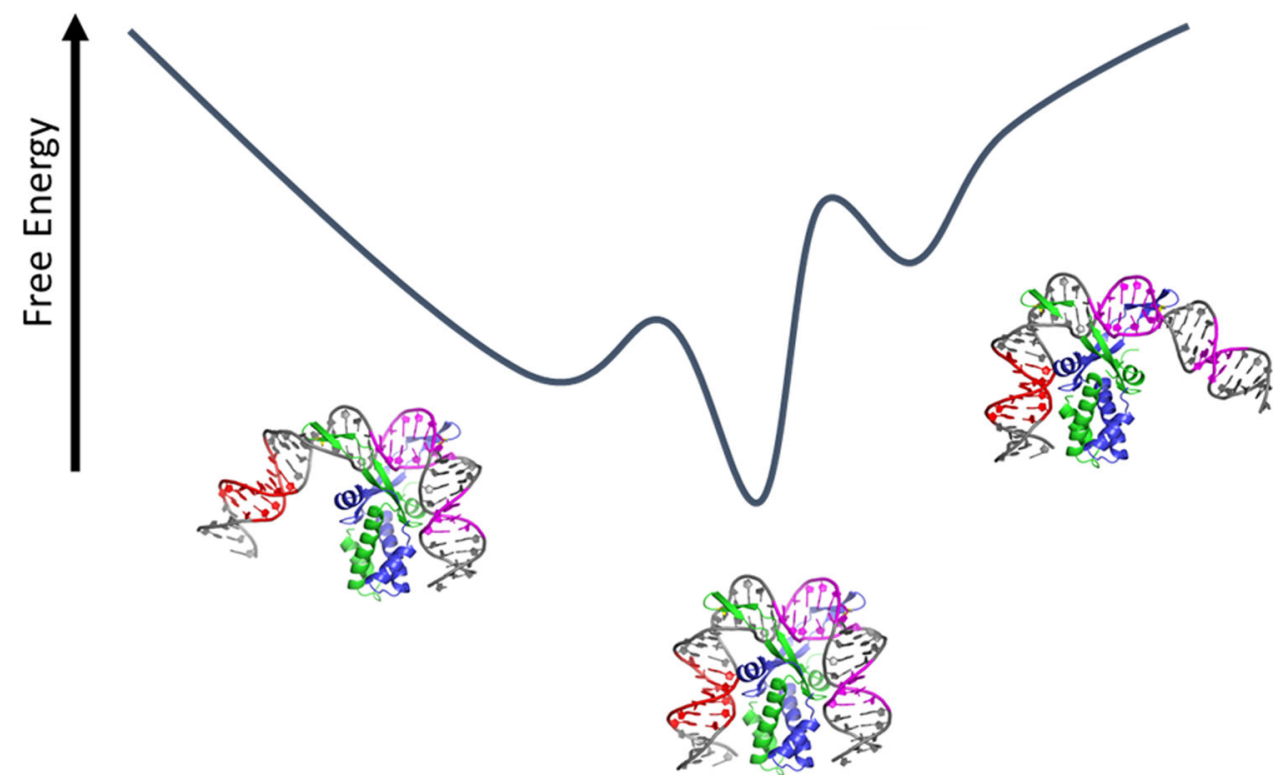

Figure 8.

Schematic representation of the free energy landscape of the specific IHF-DNA complex, with multiple conformations accessible in solution. These conformations include the most stable complex, with two DNA sites kinked, as well as conformations with one or the other side unkinked. The partially bent conformations shown are models of the low-FRET population and not based on real structural data. 

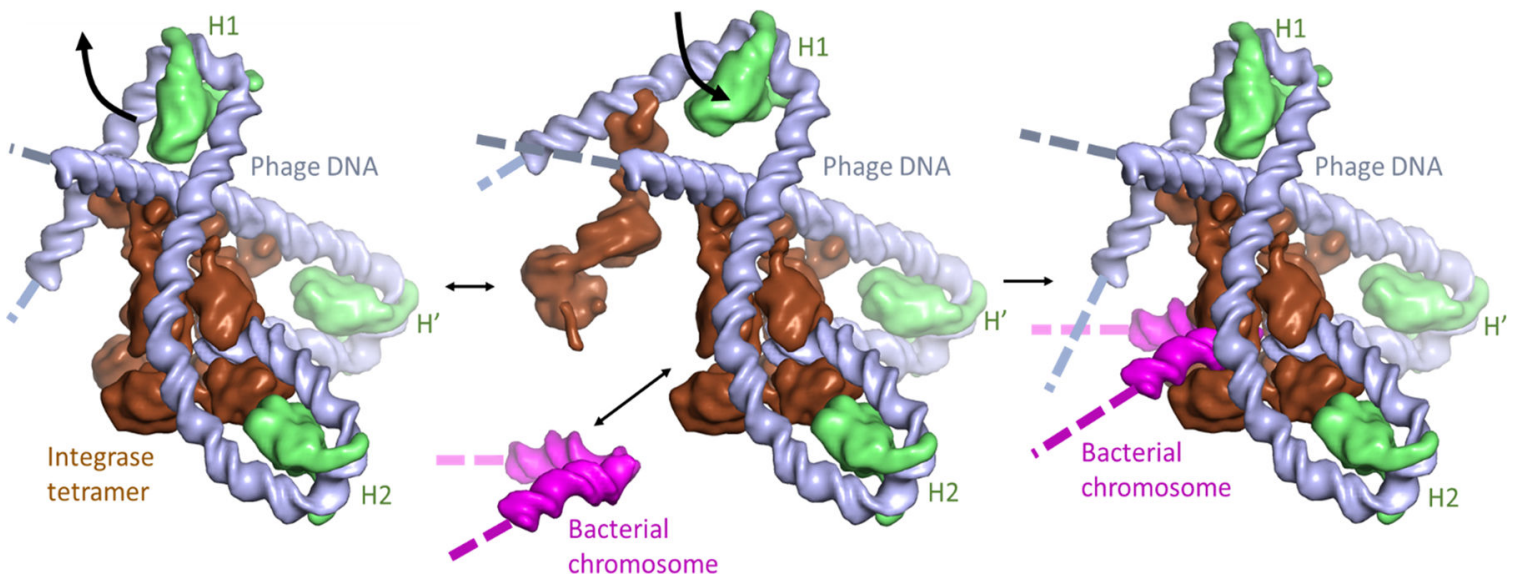

Figure 9.

Flexible DNA bending at the $\mathrm{H} 1$ site may facilitate assembly of the phage lambda integration complex. Proteins and DNA segments in the model are shown as smoothed surfaces. The "intasome" assembles on phage DNA ("attP"; gray), with 3 copies of IHF (green) bending the DNA such that the integrase tetramer (brown) can bridge multiple DNA sites. Transient flapping of the IHF-induced bend at the H1 site (center panel) allows insertion of the bacterial integration site DNA ("attB"; magenta) into the complex, which is then trapped by closure of the $\mathrm{H} 1$ bend. Note that in these images the H1 binding site is oriented such that the (missing) A-tract side is on the right, i.e. orientation of IHF relative to the DNA at the $\mathrm{H} 1$ site is flipped $180^{\circ}$ from that shown in Figure 1. 
Table 1:

DNA Constructs Used in This Study

\begin{tabular}{|c|c|c|c|c|}
\hline Construct & Sequence $^{\mathrm{a}}$ & $\begin{array}{l}\langle\boldsymbol{F R E T E}> \\
\text { at } 100 \mathrm{mM} \mathrm{KCL}\end{array}$ & $\begin{array}{c}K_{\mathrm{d}} \\
\text { at } 100 \mathrm{mM} \mathrm{KCL}\end{array}$ & $\begin{array}{c}K_{\mathrm{d}} \\
\text { at } 300 \mathrm{mM} \mathrm{KCL}^{\mathrm{b}}\end{array}$ \\
\hline $\mathbf{H}^{\prime}$ (design I) & $\begin{array}{l}5^{\prime} \text { - TGGCCAAAAAAGCATTGCTTATCAATTTGTTGCACC } \\
\text { CCGGTTTTTTCGTAACGAATAGTTAAACAACGTGGT - } 5^{\prime}\end{array}$ & $0.50 \pm 0.03$ & \begin{tabular}{|c|}
$23_{-14}^{+57} \mathrm{pM}^{\mathrm{b}}$ \\
$27 \pm 2 \mathrm{pM}^{\mathrm{c}} ; 25 \mathrm{pM}^{\mathrm{d}}$ \\
\end{tabular} & $1.9 \pm 0.1$ \\
\hline$H^{\prime}$ (design II) & $\begin{array}{l}5^{\prime}-\text { GGCCAAAAAAGCATTGCTTATCAATTTGTTGCACC } \\
\text { PCCGGTTTTTTCGTAACGAATAGTTAAACAACGTGG - } 5^{\prime}\end{array}$ & $0.41 \pm 0.01$ & -1 & $1.5 \pm 0.2$ \\
\hline H1 (design I) & $\begin{array}{l}5^{\prime} \text { - TGGCCATGCAGTCACTATGAATCAACTACTTAGACC } \\
\text { CCGGTACGTCAGTGATACTTAGTTGATGAATCTGGT - 5' }\end{array}$ & $0.25 \pm 0.01$ & $20 \mathrm{pM}^{\mathrm{e}}$ & 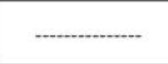 \\
\hline H1 (design II) & $\begin{array}{l}5^{\prime}-\text { GGCCATGCAGTCACTATGAATCAACTACTTAGACC } \\
\text { PCCGGTACGTCAGTGATACTTAGTTGATGAATCTGG - } 5^{\prime}\end{array}$ & $0.21 \pm 0.01$ & 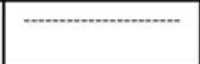 & $2.0 \pm 0.1$ \\
\hline $\mathrm{H}_{-}^{\prime}$ nAt (design I) & $\begin{array}{l}5^{\prime} \text { - TGGCCATGCAGGCATTGCTTATCAATTTGTTGCACC } \\
\text { CCGGTACGTCCGTAACGAATAGTTAAACAACGTGGI - 5' }\end{array}$ & $0.23 \pm 0.01$ & & $3.7 \pm 0.8$ \\
\hline H1_CTloop (design I) & $\begin{array}{l}5^{\prime} \text { - TGGCCATGCAGTCACTATGAATCAACTACTTAGACC } \\
\text { CCGGTACGTCAGTCTTACTTAGTTGATGAATCTGGT - 5' }\end{array}$ & $0.36 \pm 0.02$ & - & $0.06 \pm 0.02$ \\
\hline H'44A (design I) & $\begin{array}{l}5^{\prime} \text { - TGGCCAAAAAAGCATTGCTTATCAATTTGTAGCACC } \\
\text { CCGGTTTTTTCGTAACGAATAGTTAAACATCGTGGT - }\end{array}$ & $0.23 \pm 0.01$ & $7.4 \pm 2.8 \mathrm{nM}^{c}$ & \\
\hline
\end{tabular}

${ }^{a}$ The blue arrows indicate the position of the kinks in complex with IHF; the yellow- and green-highlighted thymines represent fluorescein- and TAMRA-attachment, respectively, to that base; the blue-highlighted $\mathrm{P}$ indicates attachment of Atto550 to the phosphate group; A-tract is shown in red and the consensus sequence in magenta; the position of the mutation in H'44A is indicated in purple; the position of 4-nt loop is H1_CTloop is indicated in brown.

${ }^{b-e} K_{\mathrm{d}}$ values are from $\mathrm{b}_{\text {this study, }} \mathrm{c}_{\text {ref. }}{ }^{59}$, $\mathrm{d}$-e $\mathrm{e}_{\text {stopped-flow measurements reported in }} \mathrm{d}_{\text {ref. }}{ }^{61}$ and $\mathrm{e}_{\text {ref. }}{ }^{60}$ 
Table 2:

Lifetime Measurements on IHF-DNA Complexes

\begin{tabular}{|l|c|c|c|c|c|c|c|}
\hline Construct & $\left\langle\tau_{\mathbf{1}}\right\rangle(\mathbf{n s})$ & $\left\langle\mathbf{E}_{\mathbf{1}}\right\rangle$ & $\boldsymbol{a}_{\mathbf{1}}$ & $\left\langle\boldsymbol{\tau}_{\mathbf{2}}\right\rangle(\mathbf{n s})$ & $\left\langle\mathbf{E}_{\mathbf{2}}\right\rangle$ & $\boldsymbol{a}_{\mathbf{2}}$ & $\Delta G / k_{B} T=-\ln \left(\frac{\alpha_{1}}{\alpha_{1}}\right)$ \\
\hline IHF-H' (design I) & $\begin{array}{c}1.52 \pm 0.06^{a} \\
(1.41 \pm \\
0.03)\end{array}$ & $\begin{array}{c}0.65 \pm 0.03 \\
\left(\begin{array}{l}0.67 \pm \\
0.02)\end{array}\right.\end{array}$ & $\begin{array}{c}78 \pm 3 \% \\
(66 \pm 2 \%)\end{array}$ & $\begin{array}{c}3.96 \pm 0.01 \\
(4.13 \pm \\
0.02)\end{array}$ & $\begin{array}{c}0.085 \pm \\
0.002 \\
(0.043 \pm \\
0.001)\end{array}$ & $\begin{array}{c}22 \pm 3 \% \\
(34 \pm 2 \%)\end{array}$ & $\begin{array}{c}-1.3 \pm 0.2 \\
(-0.66 \pm 0.04)\end{array}$ \\
\hline IHF-H' (design II) & $2.06 \pm 0.02$ & $0.51 \pm 0.01$ & $48 \pm 3 \%$ & $3.00 \pm 0.01$ & $0.29 \pm 0.01$ & $52 \pm 3 \%$ & $0.090 \pm 0.008$ \\
\hline IHF-H1 (design I) & $2.14 \pm 0.14$ & $0.50 \pm 0.03$ & $32 \pm 1 \%$ & $3.71 \pm 0.12$ & $0.14 \pm 0.01$ & $68 \pm 1 \%$ & $0.75 \pm 0.03$ \\
\hline $\begin{array}{l}\text { IHF-H'_nAt } \\
\text { (design I) }\end{array}$ & $1.87 \pm 0.01$ & $0.57 \pm 0.01$ & $33 \pm 1 \%$ & $3.99 \pm 0.04$ & $\begin{array}{c}0.077 \pm \\
0.001\end{array}$ & $67 \pm 1 \%$ & $0.70 \pm 0.02$ \\
\hline $\begin{array}{l}\text { IHF-H1_CTloop } \\
\text { (design I) }\end{array}$ & $1.96 \pm 0.08$ & $0.55 \pm 0.02$ & $43 \pm 3 \%$ & $3.22 \pm 0.16$ & $0.25 \pm 0.01$ & $57 \pm 3 \%$ & $0.32 \pm 0.03$ \\
\hline $\begin{array}{l}\text { IHF-H'44A } \\
\text { (design I) }\end{array}$ & $1.66 \pm 0.04$ & $0.62 \pm 0.02$ & $32 \pm 1 \%$ & $3.99 \pm 0.01$ & $0.076 \pm$ & $68 \pm 1 \%$ & $075 \pm 0.03$ \\
\hline
\end{tabular}

${ }^{a}$ Measurements were done in $100 \mathrm{mM} \mathrm{KCl}$

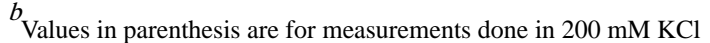

